\title{
Observations of Hail-Wind Ratios from Convective Storm Reports across the Continental United States
}

\author{
MATTHEW J. BUNKERS \\ NOAA/National Weather Service, Rapid City, South Dakota \\ STEVEN R. FLEEGEL \\ NOAA/National Weather Service, Aberdeen, South Dakota \\ THOMAS GRAFENAUER \\ NOAA/National Weather Service, Grand Forks, North Dakota \\ CHAUNCY J. SCHULTZ \\ NOAA/National Weather Service, Bismarck, North Dakota \\ PHILIP N. SCHUMACHER \\ NOAA/National Weather Service, Sioux Falls, South Dakota
}

(Manuscript received 9 July 2019, in final form 23 December 2019)

\begin{abstract}
The objective of this study is to provide guidance on when hail and/or wind is climatologically most likely (temporally and spatially) based on the ratio of severe hail reports to severe wind reports, which can be used by National Weather Forecast (NWS) forecasters when issuing severe convective warnings. Accordingly, a climatology of reported hail-to-wind ratios (i.e., number of hail reports divided by the number of wind reports) for observed severe convective storms was derived using U.S. storm reports from 1955 to 2017. Owing to several temporal changes in reporting and warning procedures, the 1996-2017 period was chosen for spatiotemporal analyses, yielding 265691 hail and 294449 wind reports. The most notable changes in hailwind ratios occurred around 1996 as the NWS modernized and deployed new radars (leading to more hail reports relative to wind) and in 2010 when the severe hail criterion increased nationwide (leading to more wind reports relative to hail). One key finding is that hail-wind ratios are maximized (i.e., relatively more hail than wind) during the late morning through midafternoon and in the spring (March-May), with geographical maxima over the central United States and complex/elevated terrain. Otherwise, minimum ratios occur overnight, during the late summer (July-August) as well as November-December, and over the eastern United States. While the results reflect reporting biases (e.g., fewer wind than hail reports in low-population areas but more wind reports where mesonets are available), meteorological factors such as convective mode and cool spring versus warm summer environments also appear associated with the hail-wind ratio climatology.
\end{abstract}

\section{Introduction}

The U.S. National Weather Service (NWS) issues short-fuse (generally $30-60 \mathrm{~min}$ ) severe thunderstorm warnings that contain impact information related to the forecast maximum surface hail size and/or wind gusts

Corresponding author: Matthew J. Bunkers, matthew.bunkers@ noaa.gov
(NWS 2018). The hail and wind information is part of the impact-based warning (IBW) initiative-started as a pilot project with 5 NWS offices in 2012, expanded to 38 (46) NWS offices in 2013 (2014), and implemented across the continental United States (CONUS) in 2016- that attempts to convey impact-based risk information (i.e., enhanced wording) associated with these two expected hazards (Hudson et al. 2013, 2015; Casteel 2016). The IBW initiative actually started after the 


\begin{tabular}{|c|c|c|c|c|c|c|c|c|c|c|c|c|c|c|}
\hline & & & & & & Wind & Gus & $\mathrm{t}[\mathrm{mp}$ & & & & & & \\
\hline & 0 & 45 & 50 & 55 & 58 & 60 & 65 & 70 & 75 & 80 & 85 & 90 & 100 & Total \\
\hline 0.0 & & & 0.00 & & & 0.07 & 0.00 & 0.01 & 0.00 & 0.00 & & & & 0.09 \\
\hline 0.25 & & & & & & 0.00 & & & & & & & & 0.00 \\
\hline 0.5 & & & 0.01 & & & 1.07 & 0.00 & 0.19 & & 0.02 & & 0.00 & & 1.29 \\
\hline 0.75 & & & 0.02 & & & 19.43 & 0.09 & 2.70 & 0.01 & 0.24 & 0.00 & 0.01 & 0.00 & 22.48 \\
\hline 0.88 & & & & & & 2.78 & 0.02 & 0.52 & 0.00 & 0.04 & & 0.00 & & 3.36 \\
\hline 1.0 & 0.01 & 0.00 & 7.17 & 0.00 & 0.22 & 38.19 & 0.10 & 3.11 & 0.03 & 0.25 & 0.00 & 0.01 & 0.01 & 49.09 \\
\hline$=1.25$ & 0.00 & & 1.45 & & 0.06 & 6.81 & 0.04 & 0.70 & 0.00 & 0.05 & & 0.00 & & 9.11 \\
\hline 1.5 & & & 1.17 & & 0.04 & 4.88 & 0.01 & 0.73 & 0.00 & 0.06 & & 0.00 & 0.00 & 6.89 \\
\hline 1.75 & & & 0.83 & & 0.02 & 3.34 & 0.02 & 0.91 & 0.00 & 0.08 & & 0.00 & 0.00 & 5.20 \\
\hline 2.0 & & & 0.13 & & 0.00 & 0.72 & 0.00 & 0.30 & & 0.04 & & 0.00 & & 1.19 \\
\hline 2.25 & & & & & & & & 0.00 & & & & & & 0.00 \\
\hline 2.5 & & & 0.09 & & 0.00 & 0.42 & 0.00 & 0.20 & 0.00 & 0.04 & & 0.00 & & 0.76 \\
\hline 2.75 & & & 0.06 & & & 0.22 & 0.00 & 0.13 & & 0.04 & & & 0.00 & 0.44 \\
\hline 3.0 & & & 0.00 & & & 0.03 & & 0.02 & & 0.01 & & & & 0.05 \\
\hline 4.0 & & & 0.00 & & & 0.00 & & 0.01 & & 0.00 & & 0.00 & & 0.02 \\
\hline 4.25 & & & 0.00 & & & 0.00 & & 0.00 & & 0.00 & & & & 0.01 \\
\hline 4.5 & & & & & & 0.00 & & & & & & & & 0.00 \\
\hline Total & 0.01 & 0.00 & 10.92 & 0.00 & 0.35 & 77.94 & 0.28 & 9.55 & 0.05 & 0.85 & 0.00 & 0.04 & 0.02 & \\
\hline
\end{tabular}

FIG. 1. Frequency (\%) of NWS hail size and wind gust IBW tags for severe thunderstorm warning issuance from 2 Apr 2010 to 8 Nov 2018 (106 659 warnings; 1 in. $=2.54 \mathrm{~cm}$ and $1 \mathrm{mph}=$ $0.45 \mathrm{~m} \mathrm{~s}^{-1}$ ). Values $>10 \%$ are highlighted in red. Image courtesy of D. Herzmann from the Iowa Environmental Mesonet at Iowa State University (http://mesonet.agron.iastate.edu/ plotting/auto/?_wait $=$ no\&q $=50$ ).

implementation of the hail and wind "tags" (which are given at the bottom of NWS warnings), with the tags implemented by about $40 \%$ of NWS offices in 2010 , reaching near $100 \%$ of all NWS offices in 2017 (D. Herzmann 2019, personal communication). Moreover, some NWS offices were including forecast hail and wind information in the body of NWS warnings in the decade prior to 2010, but they were not codified as tags at the bottom of the warning product. In light of including these tags in NWS warnings, Blair et al. (2017) compared the forecast hail size in warnings to standard and high-resolution hail observations to provide forecasters with improved guidance based on storm mode and environment. Similar peer-reviewed warning guidance is not available to forecasters for the forecast wind.

NWS offices have the option of setting default initial values for the forecast hail and/or wind information in their severe thunderstorm warnings; these values can be manually changed before transmitting warnings. Some offices might set one or both of the lowest severe thresholds as defaults for severe thunderstorm warnings [i.e., 1 -in. $(2.54 \mathrm{~cm})$ hail and/or $60-\mathrm{mph}(51 \mathrm{kt}$ or $26.8 \mathrm{~m} \mathrm{~s}^{-1}$ ) winds], while other offices may decide not to set any default thresholds so forecasters are required to make a selection based on radar, spotter, and environment information. These default hail and wind settings are apparent in NWS warnings issued from 2010 to 2018
(Fig. 1), with 1-in. (2.54 cm) and 60-mph $\left(26.8 \mathrm{~m} \mathrm{~s}^{-1}\right)$ tags collectively accounting for $38 \%$ of all tags and representing the most of any combination of hail sizes and wind gusts. Moreover, the $60-\mathrm{mph}\left(26.8 \mathrm{~m} \mathrm{~s}^{-1}\right)$ tag was used $78 \%$ of the time compared to all other wind gusts (Fig. 1). Anecdotally, forecasters have struggled more with forecasting thunderstorm wind gusts compared to forecasting hail size, in part because hail size is easier to estimate than wind gusts (e.g., Edwards et al. 2018), but also because radar-based hail signatures tend to be more reliable/robust than wind signatures (e.g., Blair et al. 2011). However, it may be possible to leverage the ratio of severe hail to severe wind reports to improve knowledge of when wind-related IBW information should be included in severe thunderstorm warnings. Specifically, if forecasters have an understanding of the climatological frequency or rarity of hail and wind events, they may have some situational awareness of the need to include one or both in their warnings depending on location, time of year, and time of day.

The storm report database has many limitations that have been well documented (Kelly et al. 1985; Weiss and Vescio 1998; Weiss et al. 2002; Doswell et al. 2005; Trapp et al. 2006; Smith et al. 2013; Allen and Tippett 2015; Edwards et al. 2018; Potvin et al. 2019; among others), with population biases being ubiquitous. Most relevant to this study, Smith et al. (2013) showed a stark contrast 
in the sample of measured (2\%) versus estimated (98\%) convective wind gusts, and Weiss et al. (2002) showed geographical biases of wind reporting based on NWS forecast areas of responsibility (geographical reporting biases affect hail too). In addition, verification strategies are influenced by available workforce and performance goals (among other things), and this could mean that searching for reports for a given warning stops after an initial verifying report is received (Amburn and Wolf 1997; Blair et al. 2011). Specifically, if hail (wind) is commonly received as the initial report, then a major concern is that wind (hail) reports could have a low bias because of this supposed practice, especially in lowpopulation areas. Nighttime can enhance this "low population" bias as this is when most people are asleep, and thus unavailable to observe and report severe weather (e.g., Maldonado-Jaime et al. 2019). Other complications with the database include that (i) the $50-\mathrm{kt}\left(25.7 \mathrm{~m} \mathrm{~s}^{-1}\right)$ severe wind criterion was not implemented by the NWS until 1970; prior to that it was $65 \mathrm{kt}\left(33.4 \mathrm{~m} \mathrm{~s}^{-1}\right)$ (Edwards et al. 2018), (ii) the NWS underwent a major radar upgrade that was mostly completed around 1996 (Crum and Alberty 1993; Crum et al. 1998), (iii) official storm reports started differentiating between estimated and measured wind gusts in 2006 (Edwards et al. 2018), (iv) the NWS changed from countybased to polygon-based warnings in October 2007 (Ferree et al. 2006; Sutter and Erickson 2010; Harrison and Karstens 2017), and (v) the definition of severe hail changed nationwide from $0.75 \mathrm{in} .(1.91 \mathrm{~cm})$ to $1.0 \mathrm{in}$. (2.54) in January $2010^{1}$ (Kramar and Waters 2010; Cavanaugh and Schultz 2012; also see http://www.nws.noaa.gov/os/ notification/scn09-52_1inch_hail_oper.txt). These temporal changes and the aforementioned regional and population biases make working with the storm report database problematic. However, if the biases are mostly consistent between the hail and wind report databases, then the ratio of the two should be less prone to these limitations and/or changes with time. Thus, this climatological information on hail-wind ratios may be useful for severe local storms forecasting (e.g., Johns and Doswell 1992).

Given the difficulty in forecasting severe convective wind gusts relative to severe hail (e.g., Jirak et al. 2014), along with the increasing focus on IBWs and decision support services by the NWS (Hudson et al. 2013, 2015), there is a need to provide better climatological guidance to forecasters on when and where

\footnotetext{
${ }^{1}$ NWS offices that serve Kansas experimented with the 1-in. $(2.54 \mathrm{~cm})$ severe hail criterion starting in 2005, with testing spreading to some other offices in the central CONUS by 2009 .
}

to include wind information in severe thunderstorm warnings. ${ }^{2}$ Previously, Kelly et al. (1985) found that more wind than hail reports occurred for the CONUS, and implicitly addressed national/regional hail-wind ratios, but they never went into detail on these ratios. It is hypothesized that the time of year/day dictates the frequency of hail versus wind reports because of changes in the environment and convective mode as the year/day progresses (e.g., Klimowski et al. 2003; Smith et al. 2012). For example, during the afternoon when thunderstorms tend to be cellular, it is expected that hail would be more common relative to wind, but in the evening this would transition to favor wind because the storm mode becomes increasingly noncellular and the cold pools become consolidated (e.g., Parker 2018). And in the spring, hail may be relatively more common than wind because of cold midlevel temperatures and climatologically strong deep-layer shear (i.e., increased probability of supercells), whereas in mid- to late summer, hail would be relatively less likely than wind because of warm low-level to midlevel temperatures and overall weaker deep-layer shear. It also is possible that orography influences the ratio of hail-to-wind reports (e.g., fewer reports of wind relative to hail in mountainous terrain where storms tend to be more cellular than linear).

The focus of this study is to examine the ratio of severe hail reports to severe wind reports across the CONUS based on time of year, time of day, and geography/orography (evaluation of the ratios by convective mode is beyond the scope of this study). Changes in the storm report database will be assessed by examining time series of the hail-wind ratios at the various breakpoints noted above, and this will help guide the choice of which period to use in assessing the spatial and temporal hail-wind ratios across the CONUS. In turn, these ratios should help inform forecasters on when and where it would be most prudent, based on climatology, to include forecast hail versus wind information in severe thunderstorm warnings. After the data and methods are introduced below, the following sections describe the effect of using measured-only gusts on the hail-wind ratios, changes in hail-wind ratios with time, and spatiotemporal results for the hail-wind ratios from 1996 to 2017.

\section{Data and methods}

All official convective storm reports from the National Centers for Environmental Information (NCEI) spanning

\footnotetext{
${ }^{2}$ It is beyond the scope of this study to compare the wind tags in the severe thunderstorm warnings to the observed wind reports in the storm database, as was done by Blair et al. (2017) for hail. Moreover, we did not examine the ratio of hail to wind tags within severe thunderstorm warnings; that is left for future study.
} 


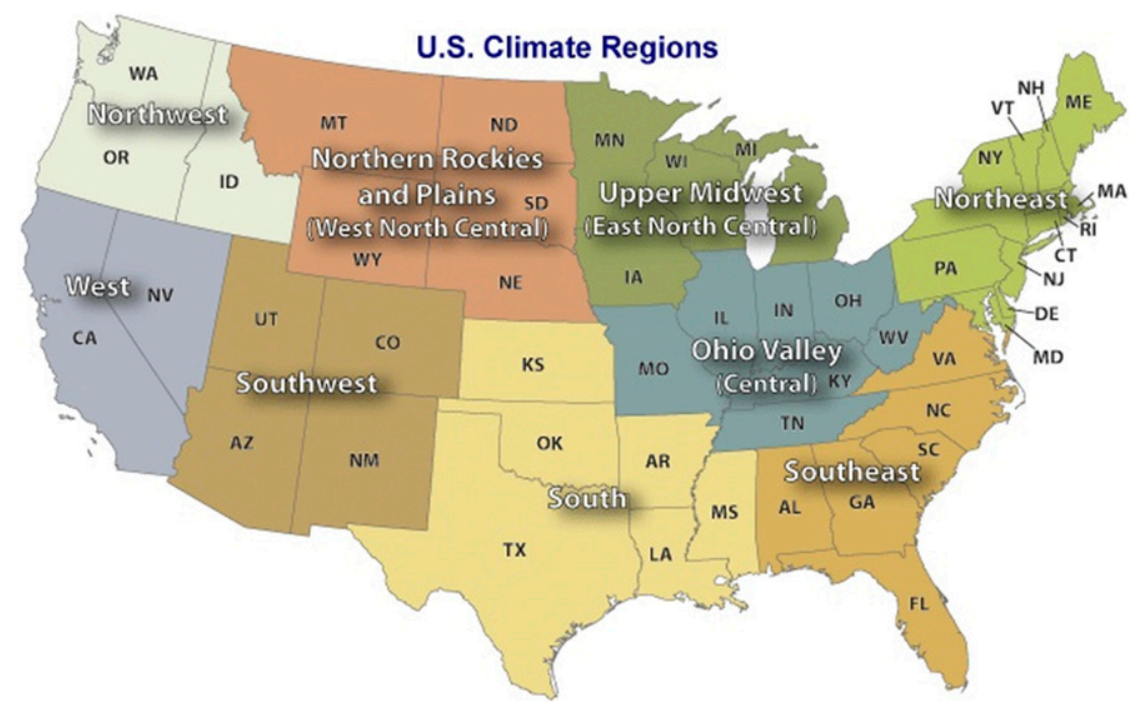

FIG. 2. NCEI's CONUS climate regions used in this study (image obtained from https:// www.ncdc.noaa.gov/monitoring-references/maps/us-climate-regions.php).

1955-2017 were used for this study. This includes measured and estimated gusts, with the latter also including gusts estimated based on damage (Edwards et al. 2018). The database does not include hurricaneproduced nonconvective wind reports; however, convective storms associated with hurricanes may result in convective wind reports. Although these reports are available in a few formats, the database maintained by the Storm Prediction Center (SPC) in geographic information system (GIS) format was used herein (see https://www.spc.noaa.gov/gis/svrgis/). This GIS-friendly database makes certain tasks-such as spatial joins and intersections-relatively easy to perform. A total of 346254 hail and 409942 wind reports were available.

As stated in section 1, known changes in the definitions and/or reporting of severe hail and wind occurred in 1970, 1996, 2006, 2007, and 2010 (at minimum). Therefore, time series of the hail-wind ratios were created for the CONUS, as well as for nine climate regions across the CONUS used by NCEI (Fig. 2). This was done in order to determine potential discontinuities at the above changepoints. Specifically, the change in the mean ratios was evaluated according to the following equation:

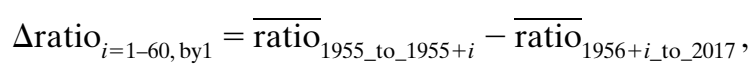

where for $i=1, \Delta$ ratio $=$ the average ratio for $1955-56$ minus the average ratio for 1957-2017; for $i=2$, $\Delta$ ratio $=$ the average ratio for $1955-1957$ minus the average ratio for 1958-2017; and for $i=60, \Delta$ ratio $=$ the average ratio for 1955-2015 minus the average ratio for 2016-17. This analysis helped determine the period used for subsequent spatial and temporal analyses.

Using results from this $\Delta$ ratio analysis, the hail-wind ratios were examined spatially on scales of the CONUS, states, and NWS forecast zones (i.e., mostly at the county or subcounty level), as well as temporally at annual, monthly, and 3-h increments starting at 0000 UTC (1800 CST). The 3-h increments were chosen instead of 1-h increments to offset the small sample size at the smallest time window.

A minimum collective total of 30 hail and wind reports (with $\geq 1$ wind report) was required for each ratio calculation in order to minimize strong ratio fluctuations at small sample sizes and to avoid an undefined ratio. This constraint is required for each of the aforementioned categories. Moreover, this means that the ratios are missing for some of the smaller forecast zones, many zones in the western CONUS, and during certain times of the day and year when reports are infrequent.

\section{Effect of using measured-only gusts on the hail-wind ratios}

Edwards et al. (2018) noted that only $10 \%$ of the severe wind gust reports from 2006 to 2015 were measured (versus $90 \%$ estimated); using the present dataset through 2017 , these values are $9.8 \%$ and $90.2 \%$, respectively. This disparity in measured versus estimated gusts would have a profound effect on the calculated hail-wind ratios, especially across the eastern CONUS 
where the estimated gusts are most numerous (Smith et al. 2013; Edwards et al. 2018).

Using the combined estimated and measured wind gusts for 2006-17 when they both were available, the hail-wind ratios are $<1$ for the eastern CONUS (Fig. 3a, blueish colors), suggesting that thunderstorm-based severe wind reports are more common than severe hail reports in this region. The ratios are $>1$ (light reddish colors) for most of the central CONUS, indicating that severe hail reports are relatively more common than severe wind reports there. Ratios then drop to mostly $<1$ for the western CONUS (except for Oregon).

The hail-wind ratios change markedly when only considering measured severe convective wind gusts (Fig. 3b, mostly red to dark red colors). The only ratios $<1$ for the entire CONUS are over Nevada and Utah, and in all but three of the states the ratios are larger than in Fig. 3a by one to two orders of magnitude. This implies that severe thunderstorm hail reports occur about 5-30 times more frequently than severe wind reports over much of the central and eastern CONUS. However, this stands in marked contrast to use of the entire complement of wind reports in Fig. 3a, especially for the eastern CONUS where all severe wind reports are 1-2 times more frequent than severe hail reports.

One may question whether Fig. $3 \mathrm{~b}$ is a fair comparison to make to Fig. 3a because the same overestimation issues for wind could be present in the hail reports. An assumption could be made that a nontrivial portion of the estimated gusts were tied to some damage (e.g., see Fig. 1 from Edwards et al. 2018). Therefore, to account for this we used $63 \mathrm{kt}\left(72.5 \mathrm{mph}\right.$ or $\left.32.4 \mathrm{~m} \mathrm{~s}^{-1}\right)$ as a lower threshold to include estimated gusts-per the suggestion of Edwards et al. (2018)—and combined those estimated gust reports with the measured gust reports to compute hail-wind ratios. The resulting ratios all decreased relative to Fig. $3 \mathrm{~b}$ because of the additional wind reports (Fig. 3c), with the most notable decreases (of $>10)$ in the Northeast and Southeast. The smallest ratio decreases ( of $<0.5$ ) occurred in the West. These hail-wind ratio decreases from Figs. $3 b$ to $3 \mathrm{c}$ are commensurate with the magnitude of the ratios; the correlation is 0.98 between the ratios in Fig. $3 \mathrm{~b}$ and the decrease of the ratios between Figs. $3 \mathrm{~b}$ and $3 \mathrm{c}$. Nevertheless, adjusting the ratios for additional wind reports still maintains high hail-wind ratios across the eastern CONUS, which remains at odds with Fig. 3a. In conclusion, considering that estimated severe wind reports are actually part of the official storm report database, and that these reports are used to verify warnings (and thus guide forecasters on what to include in the wind forecast for severe thunderstorm warnings), we chose to use all wind reports for the subsequent spatiotemporal analysis.

\section{Changes in hail-wind ratios with time}

\section{a. Pre-1996}

A visual inspection of the time series for the CONUS (Fig. 4a, orange line) reveals that there is minimal to no trend in the hail-wind ratios from 1955 to 1995, although substantial year-to-year variability in the ratios is observed. Annual reports of hail (green) and wind (blue) increased by an order of magnitude during this time, with the largest increase from 1985 to 1995 (a time with perhaps a modest increase in the hail-wind ratios). The minimum ratio of 0.40 occurred in 1970, with the average ratio being 0.07 lower for 1971-95 compared to 1955-69. This is consistent with the change in the severe wind gust criterion from 65 to $50 \mathrm{kt}$ (from 74.8 to $57.5 \mathrm{mph}$ or from 33.4 to $25.7 \mathrm{~m} \mathrm{~s}^{-1}$ ) in 1970 (Edwards et al. 2018), allowing for relatively more wind reports to be recorded after the change.

Trends similar to the CONUS are noted for the Upper Midwest, Ohio Valley, Southeast, and Northeast regions (Figs. 4g-j), especially with respect to relatively more wind than hail reports after 1970 . However, the trends differ somewhat between the CONUS and the northern Rockies/Plains, Southwest, and South regions (Figs. 4d-f), as hail reports increased more than wind reports there, especially after 1980. Finally, the Northwest and West regions did not have enough reports during this time to compute hail-wind ratios for the full time period (Figs. 4b,c), although the relative increase in wind reports is noted after 1970.

\section{b. 1996-2006}

A notable jump in the hail-wind ratios occurred from 1996 to 2006, when the annual number of CONUS hail reports increased to exceed the wind reports (Fig. 4a). The start of this period represents the completion of the installation of the WSR-88D network (Crum et al. 1998) as well as the modernization and associated restructuring of the NWS (Friday 1994). These changes led to an increased ability to observe the atmosphere, along with more staffing to gather storm reports. Possible reasons that the increase in reports was relatively larger for hail compared to wind include (i) it may have been easier to know where within a storm to seek reports for hail-relative to wind-which would have been most efficient in low-population areas; (ii) hail may have tended to be the first report most of the time; (iii) hail has a longer residence time and can take considerable time to melt, whereas severe wind is relatively instantaneous (unless it produces damage); and/or (iv) hail is easier to estimate/measure compared to wind. 

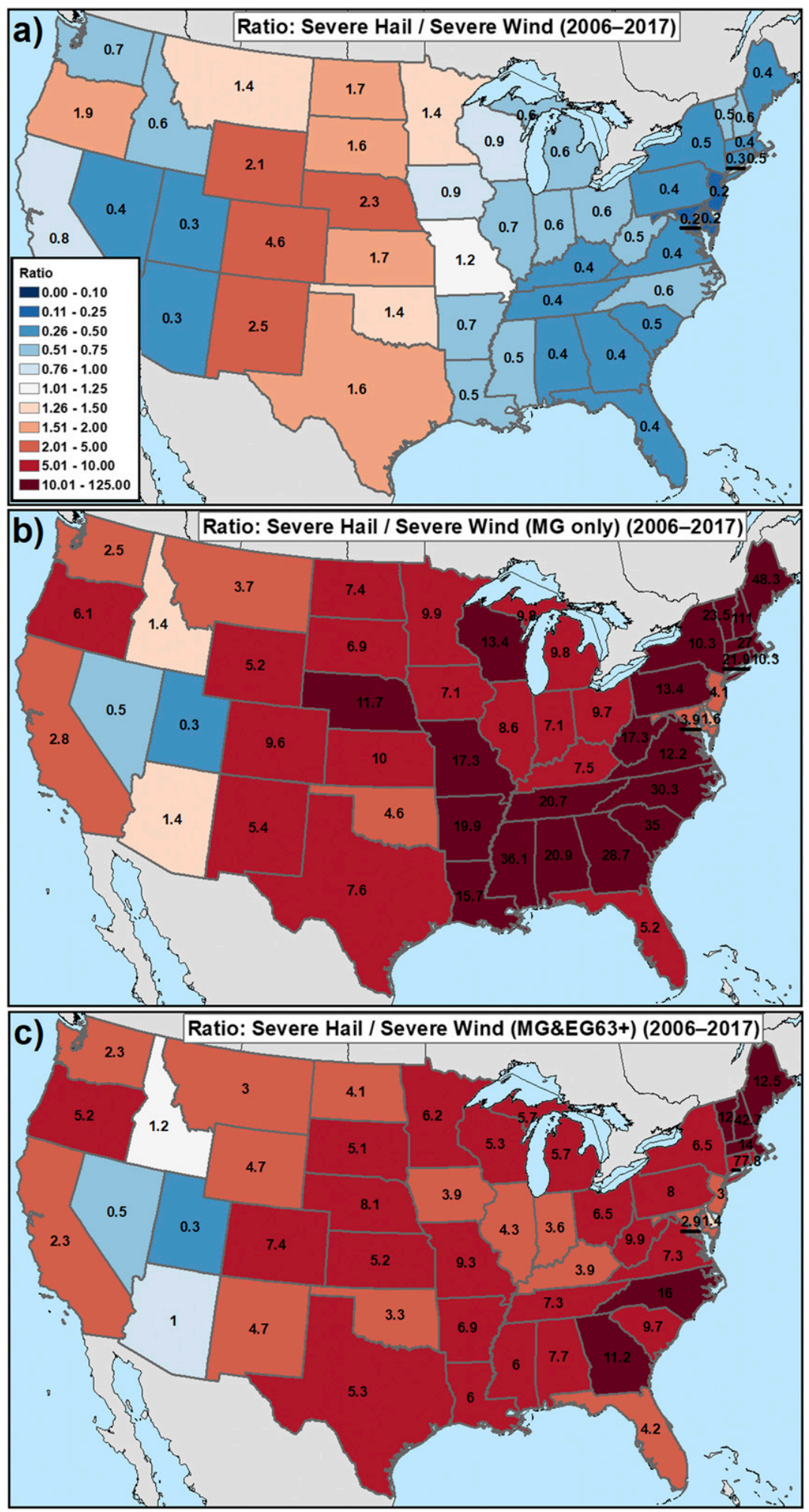

FIG. 3. Hail-wind ratios for 2006-17 using (a) all wind gust reports, (b) only measured wind gust (MG) reports, and (c) MG plus estimated wind gusts $\geq 63 \mathrm{kt}(72.5 \mathrm{mph}$ or $32.4 \mathrm{~m} \mathrm{~s}^{-1}$ ). Ratios for CT and MD are underlined for reference. The color shading for the ratios is consistent among all three panels. 

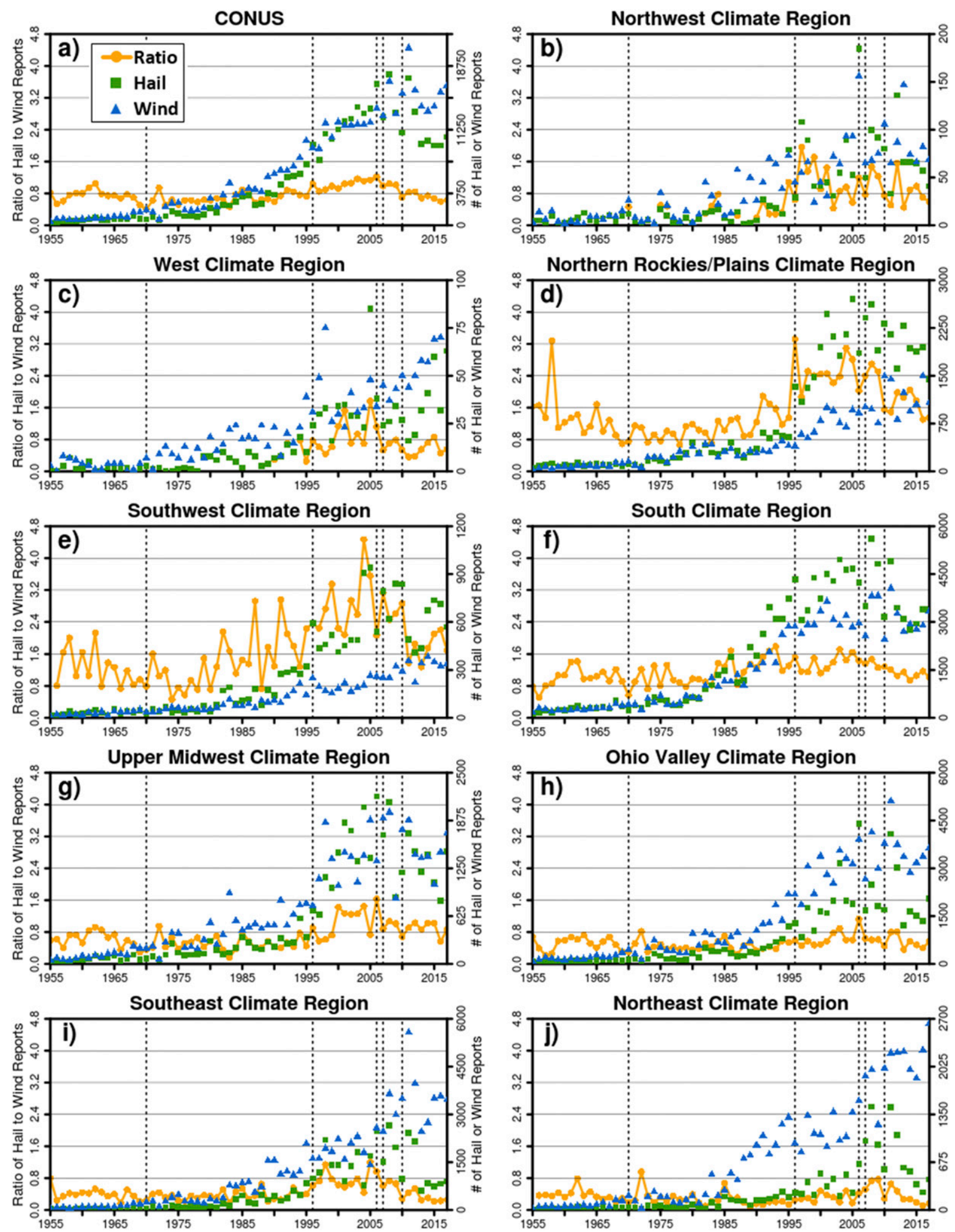

FIG. 4. Time series of the hail-wind ratios (left axis, orange, same range for all panels) and annual number of hail (green squares) or wind (blue triangles) reports (right axis, different ranges) from 1955 to 2017 for the (a) CONUS and (b)-(j) climate regions corresponding to Fig. 2. Vertical dashed lines represent breakpoints at 1970, 1996, 2006, 2007, and 2010, discussed in the text. 
Other general increases in the hail-wind ratios for this period are noted for nearly all of the climate regions, albeit the increases are early in the period for the Northwest (Fig. 4b) and mostly later in the period for the West, Upper Midwest, and Ohio Valley (Figs. 4c,g,h). The South had a more notable increase in the hail-wind ratios in the early 1990s, and this corresponds to the earlier install of the WSR-88D network in that region (Crum and Alberty 1993). The Northeast had the weakest overall increase in the hail-wind ratios (Fig. 4j).

\section{c. Post-2006}

A decrease in the CONUS hail-wind ratios was observed from 2006 to 2017, with a drop from 2006 to 2007 and another drop from 2009 to 2010 (Fig. 4a). The change to polygon warnings occurred in 2007 , and the severe hail threshold increased nationwide in 2010. Although it is difficult to be certain using only this short record, it is likely that the increase in the severe hail threshold had a notably bigger impact than the polygon change on reducing the number of hail reports during the most recent part of the record. This makes sense because, all else being equal, there should be fewer total severe hail reports when using a criterion of 1 in. $(2.54 \mathrm{~cm})$ versus $0.75 \mathrm{in} .(1.91 \mathrm{~cm})$. Moreover, since the central CONUS observes severe hail more frequently than severe wind, ratios should have started to fall after 2005 because of the experiment to increase the severe hail criterion in this area (refer to footnote 1). Indeed, this is evident in Table 1 for the Ohio Valley, South, and Upper Midwest (i.e., ratio decreases of only 0.01 to 0.08 between 2007-17 and 2010-17).

Otherwise, all of the individual climate regions exhibited ratios that were $0.05-0.90$ lower (average decrease of 0.38 ) for the 2010-17 period compared to 2007-09 (Table 1), indicating that the impact of the severe hail criterion change was larger than the impact of the change to polygon-based warnings. And even though the trend in Fig. 4 for the ratios for 1996-2006 was positive and for 2007-09 was negative, the average change in ratios between these two periods was only 0.03 (Table 1; ranging from -0.34 in the Northeast to 0.22 in the West; all other differences of ratios were from -0.13 to 0.09 ). This result generally is consistent with Brooks and Correia (2018), who found that tornado warning performance did not change significantly when switching from county-based to polygon-based warnings.

Another aspect of transitioning from county-based to polygon-based warnings is that the verification procedures also changed. Prior to 2007, one was required to verify each county in a warning-even if it was in the same warning. For example, a warning covering the intersection of four counties would require four storm reports to verify each county in the county-based warning. However, with the advent of polygons, only one report is needed to verify the entire warning. This change in verification practices impacts both hail and wind, whereas the change to 1 -in. $(2.54 \mathrm{~cm})$ hail is specific only to hail. Thus, the change in the hail criterion is expected to have a bigger effect on hail-wind ratios than the change from county-based to polygonbased warnings.

To complicate the analysis even further, the Severe Hazards Analysis and Verification Experiment (SHAVE) project operated from 2006 to 2015 (Ortega et al. 2009; Ortega 2018; also see https://www.nssl.noaa.gov/projects/ shave/). SHAVE ran from midspring to late summer each of these years, with a focus on gathering public reports of hail, wind damage, flash flooding, and frozen precipitation. Allen and Tippett (2015) found that SHAVE reports contributed from $0.5 \%$ to $2.5 \%$ of the total hail reports to Storm Data from 2008 to 2014 . $^{3}$ Not all SHAVE reports necessarily became part of Storm Data (Ortega 2018), which has been noted with other special projects as well (e.g., Blair et al. 2017). Nevertheless, it is likely that the inclusion of SHAVE reports in Storm Data contributed to some variability, especially from 2013 to 2015 when $1.5 \%-2.5 \%$ of the Storm Data hail reports originated from SHAVE, but it appears that SHAVE had a small impact overall (Fig. 4).

Finally, the inclusion of hail and wind information in warnings (starting in 2000-09), the implementation of the hail and wind tags in warnings (starting in 2010), and the IBW initiative (starting in 2012, refer to the introduction) potentially conflates the results even further. These changes, along with the hail criterion change, make it difficult to identify the exact year(s) in which the warning philosophy changed.

\section{d. Changepoint analysis of the hail-wind ratios from 1955 to 2017}

Based on the changepoint results using Eq. (1) (Fig. 5), the minimum $\Delta$ ratio for the CONUS is -0.22 and occurs in 1995, which means that the average ratio from 1996 to 2017 is greater than the average ratio from 1955 to 1995 (also see Table 1). This suggests that an appropriate breakpoint-where the biggest difference in ratios between periods exists-would be at 1996. A similar analysis using differences of consecutive 5-yr periods suggests a similar breakpoint (not shown).

\footnotetext{
${ }^{3}$ A presentation by J. Allen entitled "Hail Observations: Limitations, Oddities, and Impacts" at the 2018 North American Hail Workshop (https://www.mmm.ucar.edu/north-american-hailworkshop) had similar numbers, but from 2009 to 2015 .
} 
TABLE 1. Annual mean hail-wind ratios covering six periods discussed in section 4 for the CONUS and nine NCEI climate regions (see Fig. 2). The average (avg) and standard deviation (std) for the six periods are given in the right column. Maximum (minimum) ratios for each row are in bold (italics).

\begin{tabular}{|c|c|c|c|c|c|c|c|c|}
\hline \multirow[b]{2}{*}{ Regions } & \multicolumn{8}{|c|}{ Ratios by annual periods } \\
\hline & $1955-95$ & $1955-2017$ & 1996-2006 & 1996-2017 & $2007-09$ & $2007-17$ & $2010-17$ & $\operatorname{Avg}(\mathrm{std})$ \\
\hline CONUS & 0.70 & 0.84 & $\mathbf{1 . 0 5}$ & 0.90 & 1.02 & 0.79 & 0.72 & $0.86(0.14)$ \\
\hline Northwest & 0.49 & 0.79 & 1.03 & 0.94 & 1.16 & 0.87 & 0.78 & $0.87(0.22)$ \\
\hline West & 0.39 & 0.61 & 0.89 & 0.71 & 0.67 & 0.58 & 0.56 & $0.63(0.15)$ \\
\hline Southwest & 1.45 & 2.07 & 2.76 & 2.35 & 2.72 & 2.07 & 1.86 & $2.18(0.47)$ \\
\hline Northern Rockies/Plains & 1.14 & 1.81 & 2.47 & 2.09 & 2.53 & 1.83 & 1.63 & $1.93(0.49)$ \\
\hline South & 1.21 & 1.26 & 1.39 & 1.29 & 1.37 & 1.19 & 1.11 & $1.26(0.10)$ \\
\hline Upper Midwest & 0.50 & 0.83 & 1.06 & 0.97 & 0.99 & 0.90 & 0.86 & $0.87(0.18)$ \\
\hline Ohio Valley & 0.45 & 0.58 & 0.68 & 0.62 & 0.61 & 0.58 & 0.57 & $0.58(0.07)$ \\
\hline Northeast & 0.22 & 0.32 & 0.32 & 0.36 & 0.66 & 0.38 & 0.30 & $0.37(0.14)$ \\
\hline Southeast & 0.36 & 0.50 & 0.77 & 0.54 & 0.68 & 0.41 & 0.33 & $0.51(0.17)$ \\
\hline
\end{tabular}

Other regions with the same breakpoint as the CONUS are the Southeast and northern Rockies/Plains; the Northwest (Southwest) has a suggested breakpoint at 1997 (1991). Elsewhere, the Upper Midwest, Ohio Valley, and West have suggested breakpoints at 2000-01. Outliers are the South and Northeast with suggested breakpoints of 1984 and 2006.

The least variability in ratios among the various epochs is for the Ohio Valley and South regions, while the largest variability is in the Southwest and northern Rockies/Plains (Table 1 and Fig. 5). All but two of the nine NCEI climate regions have their minimum ratios in the earliest part of the storm report record, yet the South and Southeast have minimum ratios in the last decade
(Table 1). Also of late, nearly all regions have trended toward relatively more wind than hail reports, which is perhaps a reflection of increased mesonet coverage of wind sensors across the CONUS (e.g., Horel et al. 2002; Mahmood et al. 2017; Shulski et al. 2018), and possibly an increased population density (e.g., more people affected by downed trees). Indeed, the linear trend of the percent of measured convective wind gust reports (relative to the total of measured plus estimated gusts) is positive across most of the CONUS from 2006 to 2017 (Fig. 6), with regional correlation coefficients ranging from 0.55 to 0.96 for all of the western and much of the central CONUS (Fig. 6a); this is consistent with increased mesonet coverage. From a spatial perspective,

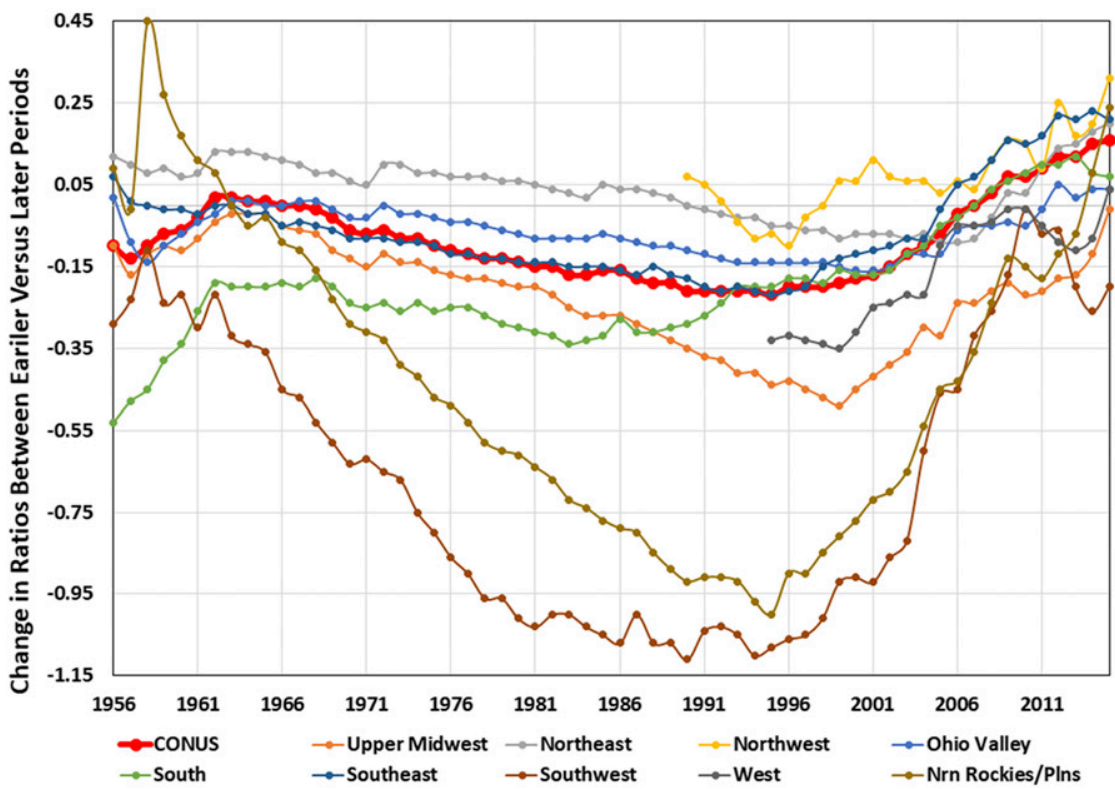

FIG. 5. Changes in the mean hail-wind ratios between earlier vs later periods according to Eq. (1). Negative values mean that the ratio is larger for the later period than for the earlier period [see discussion in section $4 \mathrm{~d}$ ]. 

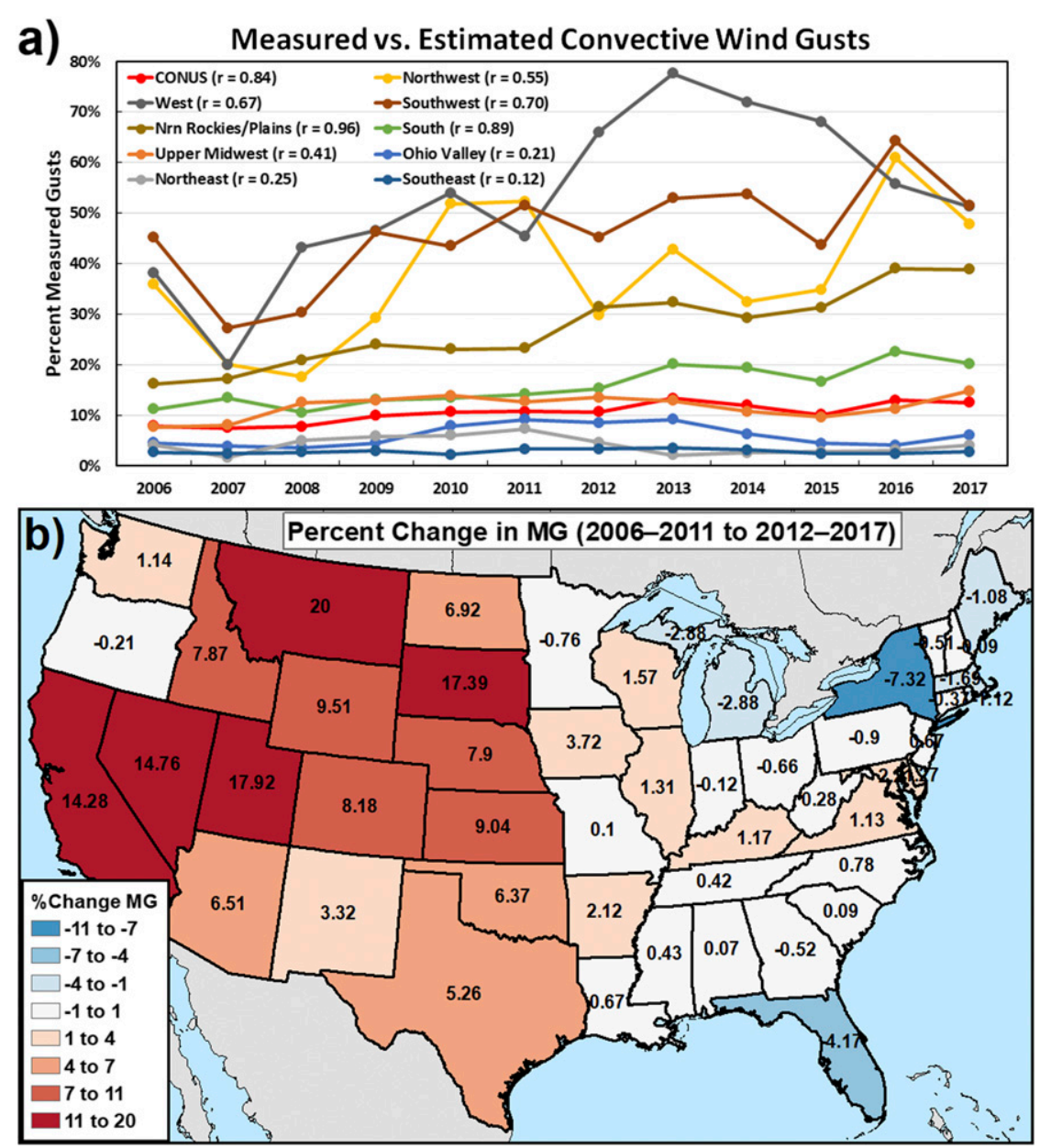

FIG. 6. (a) Percent of measured convective wind gusts (MG) compared to the total convective wind gusts [MGs plus estimated wind gusts (EGs)] across the CONUS and for the nine NCEI climate regions for 2006-17. Correlation coefficients $(r)$ for the trend line of each time series are given in the legend. The color scale matches that in Fig. 5. Recall that MGs began being reported in Storm Data in 2006. (b) Percent change in the proportion of MGs to EGs between 2006-11 and 2012-17. Values $>0$ mean that MGs were recorded relatively more frequently than EGs during the latter period.

the increase in measured gusts is much more pronounced over the western CONUS compared to the eastern CONUS (Fig. 6b, consistent with the correlation coefficients in Fig. 6a), which also is in agreement with Edwards et al. (2018, their Fig. 7) who found relatively more measured gusts in the western CONUS. Trends in measured versus estimated gusts are relatively flat, and in some states negative, across the eastern CONUS (Fig. 6). Based on data from MesoWest (A. Jacques 2019, personal communication), there has been an increase with time of stations that report wind information (Fig. 7a), with areas of dense mesonets across the CONUS (Fig. 7b).

\section{e. Summary of hail-wind ratio time series}

Clearly the changes in the hail-wind ratios with time are substantial (more so for some regions than others,
Table 1 and Fig. 5), and thus make working with the storm report database problematic. The most recent period that is least affected by these changes is 2010 17 (Figs. 4 and 5), which severely limits the number of reports that can be used (i.e., $26.1 \%$ and $30.7 \%$ of the total for hail and wind, respectively). Extending the start of the period used to the beginning of the NWS modernization (circa 1996) yields $76.7 \%$ and $71.8 \%$ of the total for hail and wind, respectively. However, the ratios for 1996-2017 are larger than the ratios for 2010-17 for all regions; this difference is most influenced by the 1996-2006 period when hail reports were at a relative maximum compared to wind (Table 1).

A comparison of the state-based hail-wind ratios for 1955-2017, 1996-2017, and 2010-17 shows that—despite 

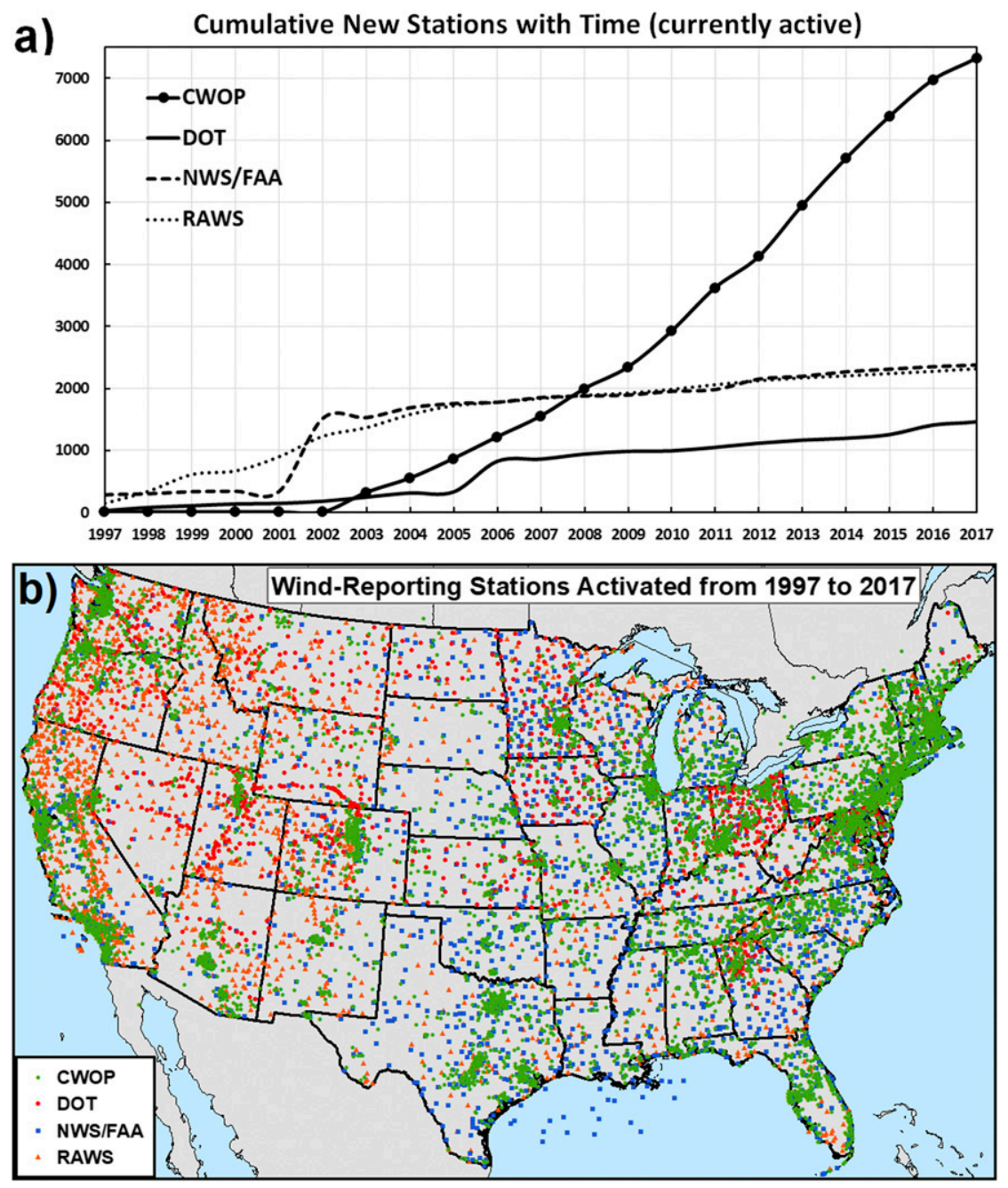

FIG. 7. (a) Cumulative new stations available to MesoWest (Horel et al. 2002) from 1997 to 2017 for the Citizen Weather Observer Program (CWOP), Department of Transportation (DOT), NWS/Federal Aviation Administration (FAA), and Remote Automated Weather Station (RAWS) observations. Mesonets not reporting to MesoWest are not indicated in this chart. (b) Locations of the CWOP, DOT, NWS/FAA, and RAWS stations coming online between 1997 and 2017. Data are courtesy of Alexander Jacques at the University of Utah.

some modest variability - the ratios are relatively consistent (especially spatially) among these three periods (Fig. 8). For example, ratios $\geq 1$ are consistent across most of the central CONUS and Oregon for all three periods, with ratios $<1$ for all of the eastern CONUS and parts of the western CONUS. An examination of the 1955-96 period shows that it compares well spatially to 1955-2017, but with ratios averaging 0.21 lower for the earlier period (not shown). Given that about threefourths of the observations are retained when beginning at 1996, this represents a viable starting point for the analysis, and thus ratios for 1996-2017 are used for the remainder of this study.

\section{Spatiotemporal results for hail-wind ratios, 1996-97}

\section{a. Spatial analysis by NWS forecast zones}

The NWS forecast zones, with their relatively small size compared to states, were used to assess the annual hail-wind ratios in terms of geographical and/or orographic distribution. Forecast zones are the scale of a county, and sometimes subcounty scale based on climate, geography, and population. They are used to convey average forecast information for a given area, as opposed to specific forecast information for a point. 

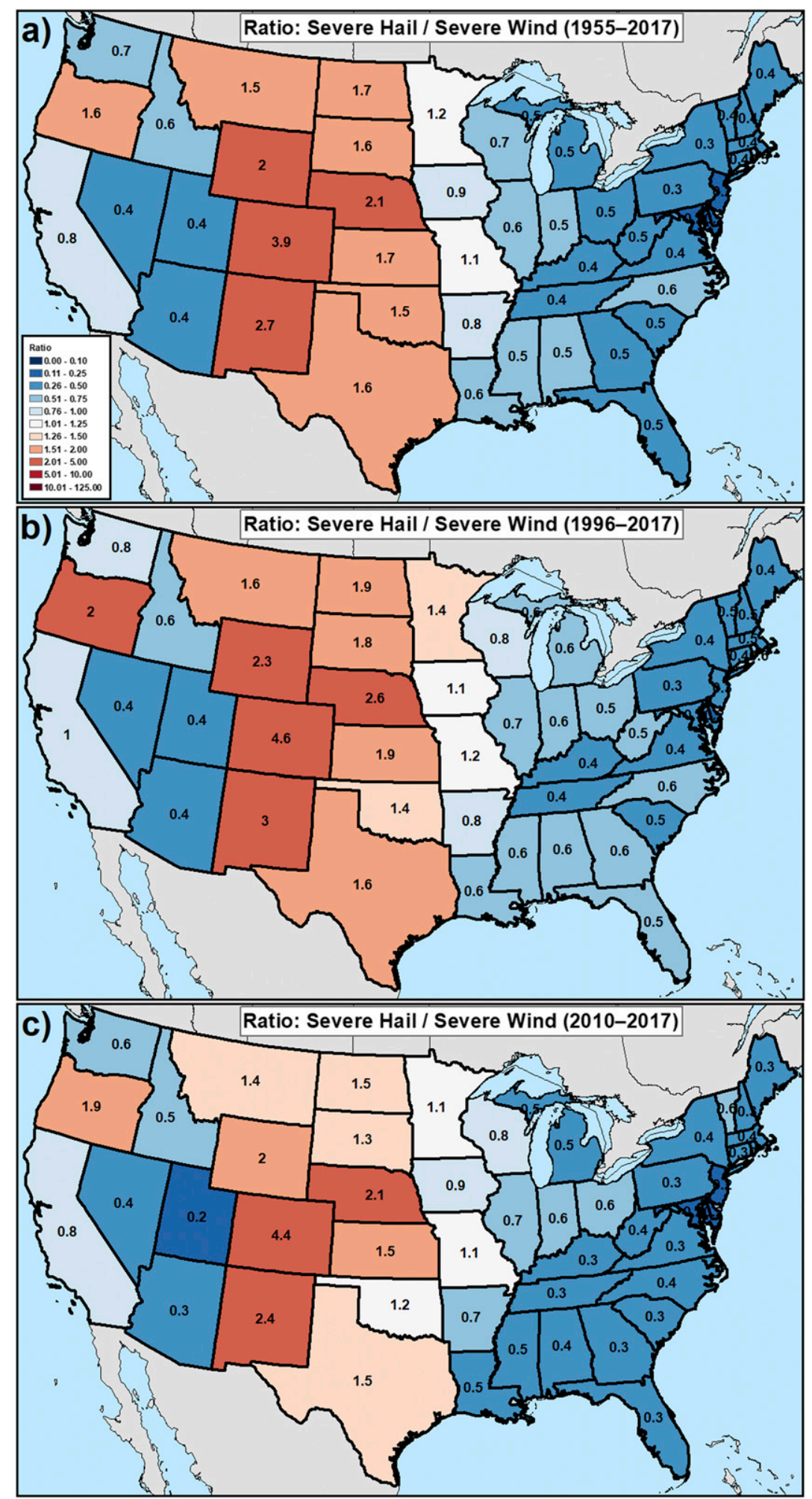

FIG. 8. Hail-wind ratios for (a) the period of record, 1955-2017, (b) 1996-2017, and (c) 2010-17. The color shading is the same as in Fig. 3. 


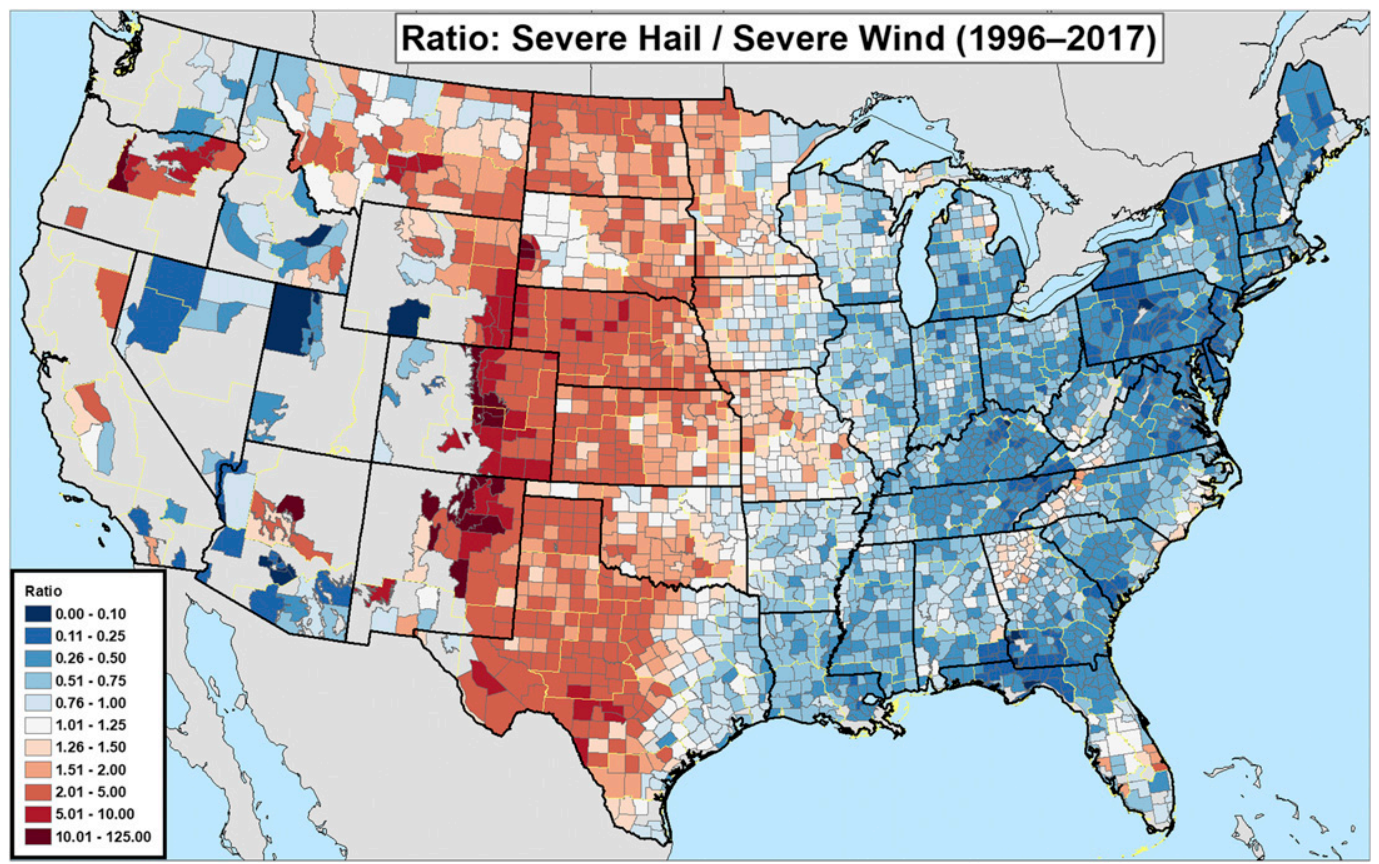

FIG. 9. Hail-wind ratios by NWS forecast zones during 1996-2017. The color shading is the same as in Fig. 3. NWS CWA boundaries are delineated by thin yellow lines. Ratio values are missing where the sample size is $<30$ and/or there are no wind reports. Note that labels are not given for the zones.

A prominent signal in this forecast zone analysis is the enhancement of ratios along and just to the lee of the eastern slopes of the Rocky Mountains from New Mexico to southeastern Wyoming, and then into central Montana (Fig. 9). ${ }^{4}$ These ratios remain relatively enhanced eastward across much of the high plains from western Texas through eastern Montana, albeit with pockets of somewhat lower ratios such as in the Oklahoma Panhandle, the western South Dakota plains, and parts of northeastern Montana (mesonets cover some of these areas, not all of which are indicated in Fig. 7b). These ratios thus highlight areas of relatively more severe wind reports in a region that frequently receives severe hail.

Some other local maxima in ratios-that appear to be associated with orography-are over parts of the (i) Appalachian Mountains from northern Georgia to southwestern Virginia and southern West Virginia, (ii) Black Hills of South Dakota, (iii) Cascade, Ochoco, and Blue Mountains from central to northeastern Oregon, (iv) mountain ranges southeast of the Snake River Plain in Idaho, (v) northern Sierra Nevada Mountains in northeastern California (albeit, the geographical extent

\footnotetext{
${ }^{4}$ Fig. 9 also was broken down into the periods shown in Fig. 8 and the spatial patterns are very similar among the three epochs.
}

and sample size are small), and (vi) Big Horn Mountains and Mogollon Rim across central Arizona. More hail (relative to wind) might be expected in higher elevations where the atmosphere is cooler and drier, which favors hail formation and maintenance (e.g., cold enough for hail to form, less melting because of evaporative cooling, and less distance for hail to fall to the ground). Again, the ratios really accentuate these orographic features-versus when looking at the hail and wind reports separately.

Somewhat more subtle ratio-topography relationships appear to exist over far southern California and central New York, for example. Elsewhere, in parts of the Upper Peninsula of Michigan and northeastern lower Michigan, localized maxima appear to be associated with lake-breeze convection off the Great Lakes, and aligns with the greatest regional lightning density (Fleegel and Dutter 2012, poster available online at https://www.weather.gov/mqt/lightning_climo). However, other local maxima in ratios that do not have a clear relationship to orography include central Florida, southeastern North Carolina, and southeastern New Hampshire. The ratios in these areas highlight opportunities for further research.

The sample size is large enough such that ratios exist for most of the zones in the central and eastern CONUS, with a few pockets of no ratios because of a lack of 


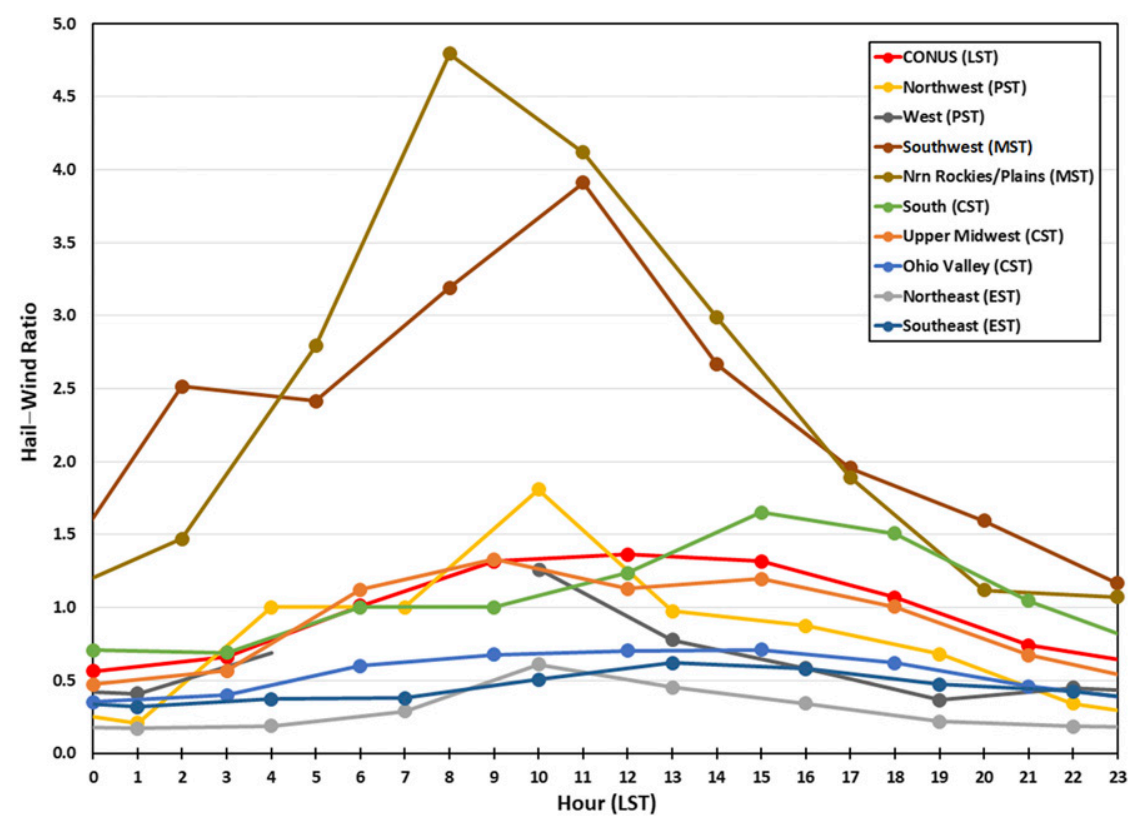

FIG. 10. Hail-wind ratio time series for the CONUS (LST) and the nine NCEI climate regions during 1996-2017. Data are grouped into 3-h bins to account for small sample sizes during the overnight, and the time corresponds to the dominant time zone for each region (indicated in the legend). Note the data points are valid for the 3 -h period starting at that time, and the West region is not plotted for 0400-0700 and 0700-1000 LST because of insufficient data. The color scale matches that in Fig. 5.

reports (likely because of low population, ${ }^{5}$ small zones, and/or complex terrain). Some of the lowest ratios are over the central and eastern Ohio Valley, the Northeast, and parts of the Southeast. This makes sense given the propensity for quasi-linear convective systems (QLCSs) across much of this area (Smith et al. 2012); however, other diurnally driven convective modes also occur here during the warm season that may contribute to enhanced wind reports. Otherwise, the derecho climatology from Coniglio and Stensrud (2004) is consistent with the lower ratios across parts of the Upper Midwest into Pennsylvania, as well as the subtle minimum in ratios across northeastern Oklahoma into northern Arkansas.

The lack of convective storm reports across much of the western CONUS results in the absence of calculated ratios in this area. Where they do exist, ratios are smallest over flatter and/or lower-elevation areas such as southern/western Arizona, parts of southeastern

\footnotetext{
${ }^{5}$ The correlation between the number of wind reports and population on a county basis is 0.26 ( 0.10 for hail versus population), whereas the correlation between the hail-wind ratio and the area of the county is 0.18 . This implies that wind reports (and to a lesser extent, hail) are more common as the county population increases, but wind reports are less common (relative to hail reports) as the county area increases.
}

California, parts of the Idaho Panhandle across the Snake River Plain, northwestern Nevada, northwestern Utah, eastern Washington, and south-central Wyoming. These areas may have benefited from increased mesonet coverage in the western CONUS (Figs. 6b and 7b; Horel et al. 2002) that allows for more wind measurements (compared to areas with limited mesonet coverage). Not all flatter/lower areas have small ratios, however, as much of the central San Joaquin Valley in California has ratios $>1$. This is an area of the West that has been documented as having supercell thunderstorms (Monteverdi and Quadros 1994; Monteverdi and Johnson 1996), and thus this area would be relatively more likely to experience hail-producing storms (e.g., Klimowski et al. 2003).

Finally, in general there are no obvious boundaries/ discontinuities between adjacent NWS forecast offices as was observed in Weiss et al. (2002) for wind reports (refer to the thin yellow lines in Fig. 9), which suggests that the ratios may be somewhat immune to this artifact. A few exceptions would be in western South Dakota and northern Georgia where there are some subtle signs of NWS boundaries. There are, however, more notable differences between adjacent zones, which we suspect are due in part to the availability of sensors that measure wind (i.e., lower ratios in zones where wind sensors are 


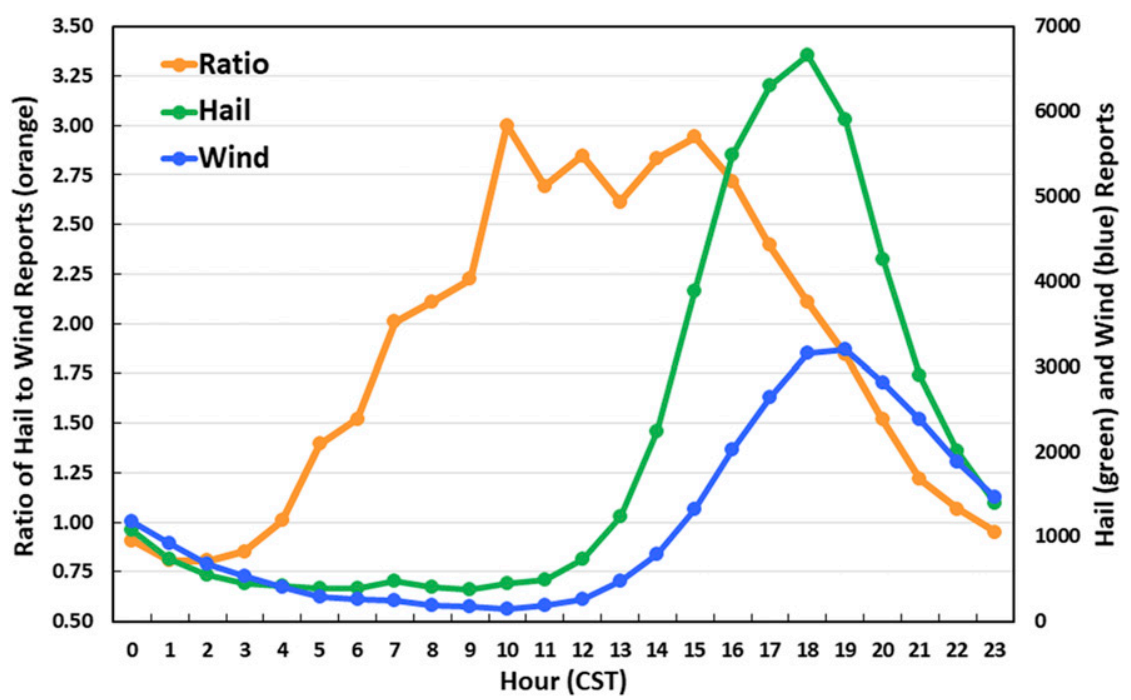

FIG. 11. Hourly (CST) hail-wind ratio time series (left axis, orange) and hail (green) and wind (blue) reports (right axis) for the central plains (i.e., the states of KS, OK, and NE) during AprilAugust 1996-2017. The total number of hail and wind reports is 49177 and 27 543, respectively.

available), as well as local topographical and population differences.

\section{b. Diurnal analysis by NCEI climate regions}

The diurnal analysis of hail-wind ratios was done by NCEI climate regions in order to maintain a reasonable sample size; the use of NWS county warning areas (CWAs, which define an NWS's area of responsibility) would have limited the analysis to the central/eastern CONUS. Despite this broader analysis, there still is a data gap for the West region from 0400 to 1000 LST (Fig. 10).

Overall, the ratios peak from 0800 to 1800 LST (Fig. 10), with all but two of the regions (i.e., the Ohio Valley and South) having maximum ratios from 0800 to 1500 LST. This is the time of day, climatologically, when thunderstorms are developing, so hail reports are relatively more common during the early phases of convective evolution. The CONUS as a whole sees a maximum in ratios from 1200 to 1500 LST (roughly in the middle of the time for all regions), and is weighted most by the South, Ohio Valley, and Southeast. The ratios are $>1$ for the Southwest and northern Rockies/Plains for the entire diurnal cycle (Fig. 10), and they are from 2.4 to 4.8 in these two regions between 0500 and 1700 LST, which is considerably higher than for all other regions. Thus, hail is reported much more frequently in these two regions at most hours of the day, and especially in the morning through midafternoon. The only other regions to exhibit ratios $>1$ at any time of the day are the Northwest, West, South, and Upper Midwest. The peak ratios at 1000-1300 LST for the Northwest and 1100-1400 LST for the Southwest are consistent with the typical midday to early afternoon development of convection over the mountains (Banta 1990), whereas the peak ratios for the South and parts of the Ohio Valley at 1500-1800 LST may be related to later convective initiation owing to capping from the elevated mixed layer (Carlson et al. 1983).

The minimum ratios occur from 2300 to 0600 LST (except for the West, which is at 1900-2200 LST). This is 10-16 h later than the maximums (Fig. 10), and seven of the nine regions have minimums from 2300 to 0400 LST. It is during this time (and especially from 2300 to 0200 LST) when the ratios from the Southwest and northern Rockies/Plains become relatively close to the ratios from the other regions. Thus, during the overnight the number of hail reports decreases relative to wind reports. This can be explained partly by discrete convection growing upscale into mesoscale convective systems and QLCSs as the cold pools merge; QLCSs are known to produce more wind relative to hail reports (Klimowski et al. 2003; Ashley et al. 2019). Interestingly, MaldonadoJaime et al. (2019) found in a regional study that the detection of wind events lags behind hail events regardless of time of day, so the fact that the ratios decrease at night is consistent with a real increase of wind relative to hail (even though hail still may be reported more often than wind in places). Therefore, there likely are both meteorological and nonmeteorological reasons for the relative minimum in hail-wind ratios overnight.

Reif and Bluestein (2017) found that hail is relatively more common than wind (ratio about 1.5) for events where convection initiates overnight in the central plains. Moreover, Reif and Bluestein (2017) and Stelten 

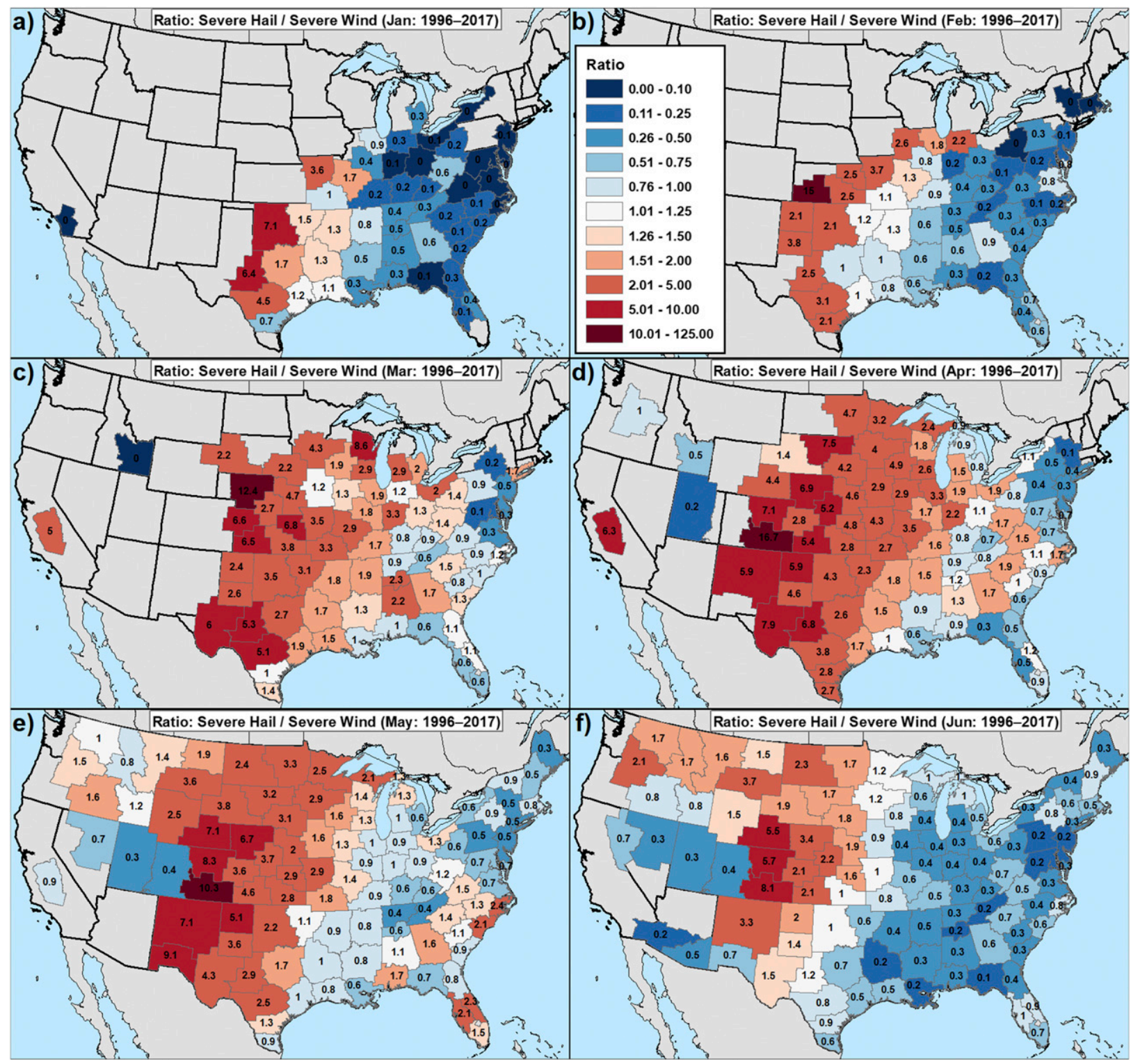

FIG. 12. Hail-wind ratios by NWS CWAs during 1996-2017 for (a)-(1) January-December. The color shading is the same as in Fig. 3 and consistent among all panels.

and Gallus (2017) noted that convective initiation has a secondary peak overnight in the central plains between 0400 and 0800 UTC (2200 and 0200 CST). This secondary convection may form after, or separate from, QLCSs and other large convective systems. Thus, this new convection may be more prone to produce hail given that cellular modes tend to be favored. To investigate this possibility, hourly hail-wind ratios for AprilAugust were constructed for a subdomain of the central plains (Kansas, Oklahoma, and Nebraska) that is common to the two above studies. The same general characteristics from the CONUS regions (Fig. 10, lowest ratios overnight and highest ratios from the late morning to midafternoon) are apparent over this central plains subdomain (Fig. 11). In addition, after 0100 CST the ratio begins to increase slightly, and then more sharply after 0300 CST, immediately after the peak in convective initiation across the central plains. Nevertheless, this is a small signal given the low number of severe convective reports during this time of day.

\section{c. Monthly analysis by NWS county warning areas (CWAs)}

The monthly hail-wind ratio coverages show a gradual expansion northward and westward from winter to spring, and then westward from spring to summer 


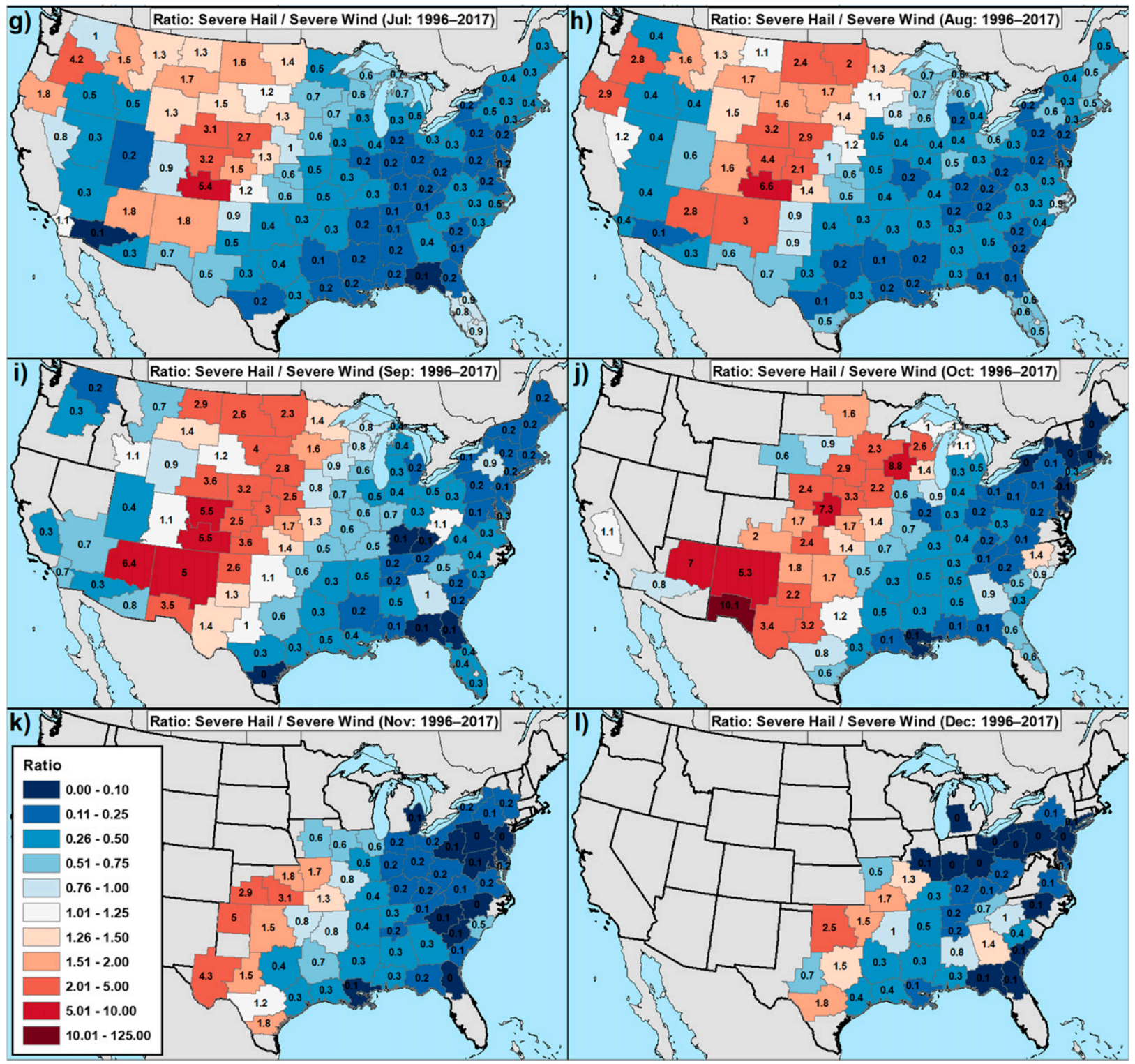

FIG. 12. (Continued)

(Fig. 12), consistent with the thunderstorm climatology (e.g., Doswell et al. 2005). During winter there is a notable enhancement of the ratios over the southern plains into parts of the western Ohio valley (Figs. 12a,b,l). Values near zero over parts of the eastern CONUS indicate that only severe wind reports (with little to no hail) are received during this time of year, whereas ratios of about 1-5 over the southern plains/Ohio Valley indicate hail is the most likely report there. A few higher/outlier values over the western fringes (e.g., ratios 7.1 and 15 in Figs. 12a and 12b in western Oklahoma and southwestern Kansas, respectively) may be due in part to a smaller sample size. The small ratios overall are consistent with the relative lack of buoyancy/convective available potential energy (CAPE) during the winter season (e.g., Rogers et al. 2014), and thus weaker updrafts and nonsevere hail.

Spring features the overall highest hail-wind ratios for the year, with ratios of about 2-9 over the central CONUS and ratios $>1$ for about half of the eastern CONUS (Figs. 12c-e). These relatively high ratios are consistent with the time when midlevel lapse rates are climatologically the largest for many locations in the central and eastern CONUS (Rogers et al. 2014), which is favorable for hail occurrence given the seasonally cool surface temperatures. Some notable variability 


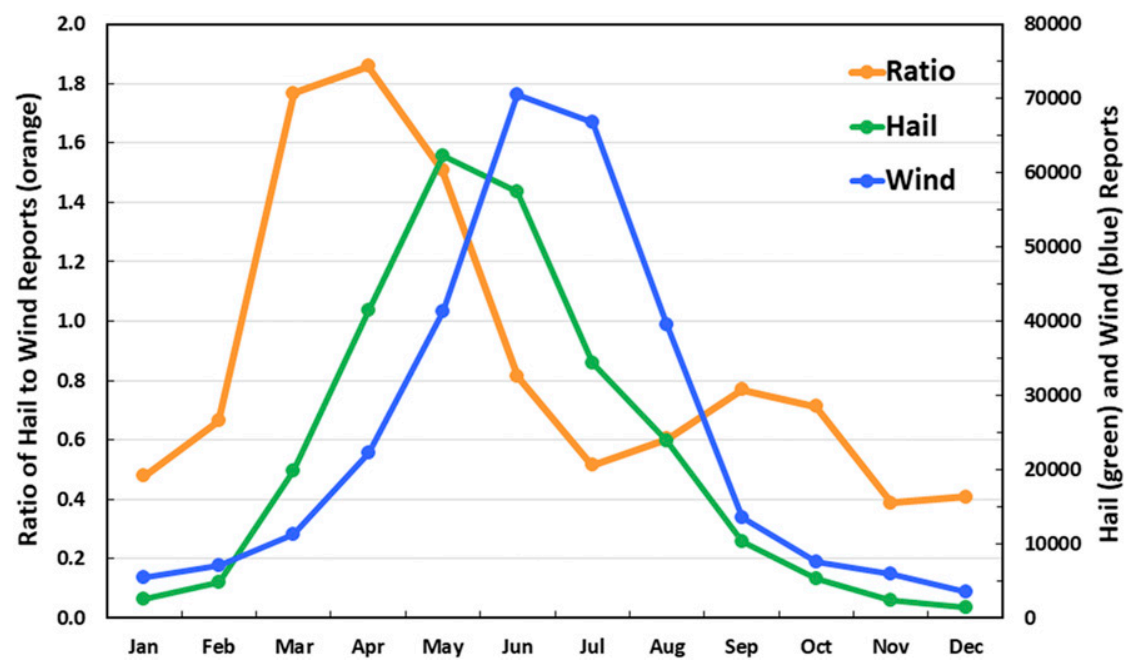

FIG. 13. As in Fig. 11, but for monthly hail-wind ratio time series for the CONUS. The total number of hail and wind reports is 265691 and 294 449, respectively.

between adjacent CWAs also exists; some examples include 2.7 versus 12.4 in Nebraska/Kansas in March (Fig. 12c), 1.4 versus 7.5 in South Dakota and 2.8 versus 16.7 in Colorado/Kansas in April (Fig. 12d), and 3.6 versus 10.3 in Colorado/Kansas in May (Fig. 12e). This is consistent with findings from Weiss et al. (2002), who noted variability in severe wind reports between adjacent CWAs, albeit on an annual basis. This variability also might be influenced by sample size and/or a few events with many severe storm reports [e.g., as in the Great Basin derecho documented by Corfidi et al. (2016)]. Otherwise, modest CWA-to-CWA variability of the hail-wind ratios is present across parts of the eastern CONUS. In the West, there is a notable uptick of storm reports from April to May, as well as a substantial decline in the hail-wind ratio during that time for the San Joaquin Valley.

Summer experiences an overall decline in the hailwind ratios compared to the spring, with minimum ratios occurring in July for $57 \%$ of the CONUS when considering the May-August period (Figs. 12f-h); August experienced minimum ratios for $36 \%$ of the CONUS. This is a time of year when large-scale convective systems and QLCSs are relatively more frequent than discrete/isolated thunderstorms, with derechos increasingly common (e.g., Coniglio and Stensrud 2004; Guastini and Bosart 2016). Weaker large-scale forcing also may lead to "irregular" convective systems that result in small $(<0.25)$ hailwind ratios (Klimowski et al. 2003). Furthermore, the midlevel lapse rates decrease climatologically toward July and August (Rogers et al. 2014), which is less favorable for hail than are steeper lapse rates; and deep-layer shear is at a climatological minimum during this time of year, which is relatively unsupportive of supercells. Finally, lower ratios over the southwestern CONUS during the summer are coincident with the monsoon season.

Hail-wind ratios continue to decrease in coverage and general magnitude (mostly over the eastern CONUS) throughout the fall (Figs. 12i-k). The lowest ratios for the year occur in November and December, straddling the fall/winter seasons. This is consistent with environments of high shear and low buoyancy (Sherburn and Parker 2014), which tend to favor more wind compared to hail. Curiously, the lower hail-wind ratios also exist over small parts of the northern plains in the fall (possibly a reflection of local use of non-NWS surface observations), despite the region experiencing mostly higher ratios.

The time series of CONUS hail-wind ratios by month (Fig. 13, orange line) confirms that the largest ratios, in aggregate, are in the spring (March-May), and the lowest warm-season ratios are in the summer (July-August). The number of wind reports across the CONUS typically exceeds the number of hail reports annually (by about $1300 \mathrm{yr}^{-1}$ from 1996 to 2017); however, the number of hail reports increases faster in the spring relative to wind reports (Fig. 13), thus yielding the maximum in ratios at that time. By summer the convective wind reports are at a relative maximum as hail reports have peaked and begin a rapid decline, resulting in the summer minimum in ratios. Then, during the fall, the number of wind reports decreases rapidly such that the CONUS hail-wind ratio displays a secondary peak of 0.77 in September, but then it drops back to a minimum around 0.4 in November-December. Collectively, the ratios help confirm other climatological 
studies of seasonal variations in hail and wind reports, while highlighting relative maxima/minima in hail versus wind reports.

\section{Summary and conclusions}

Clearly, there are many artifacts, biases, and limitations associated with the convective storm report database-something that this study reinforces from previous research. These complications make it difficult to draw meaningful conclusions from the present study. Nevertheless, when assessing the nonmeteorological changes with time, along with the relative reporting of hail versus wind (i.e., hail-wind ratios), the following summary statements can be made:

- The hail-wind ratios are one to two orders of magnitude larger when using only measured wind gusts versus using all wind gusts (i.e., estimated plus measured); the most notable differences in these ratios are across the eastern CONUS. Accounting for the high bias in estimated wind gusts noted by Edwards et al. (2018) reduces this difference by an order of magnitude, but still suggests that severe hail is much more common than severe wind over most of the CONUS.

- Changes in hail-wind ratios were noted in 1970 (slight decrease because the severe wind gust criterion was lowered), the early to mid-1990s (increase associated with the advent of new radars and NWS office modernization), 2007 (slight decrease with a change from county to polygon warnings), and 2010 (decrease because the severe hail criterion was raised nationwide). The early to mid-1990s represent the time with the most notable change in hail-wind ratios for the period of record, followed closely by 2010 .

- Ratios tend to be largest (i.e., relatively more hail than wind) in areas of topography or complex terrain, as well as the high plains-versus over lower elevations. Some of this difference in ratios may be related to population density and the availability of mesonets; lower population density results in relatively fewer wind reports than hail, but the availability of mesonets yields relatively more wind reports. However, there also are signals related to convective mode. For example, relatively low hail-wind ratios exist where QLCSs are climatologically common and relatively high ratios exist over some lower elevations where supercells tend to be common.

- Diurnally, the ratios are largest from the late morning through midafternoon when convection typically is in the early stages of evolution, whereas the ratios are smallest during the late overnight when convection is organized into larger/linear convective systems. The Southwest and northern Rockies/Plains have hail-wind ratios that remain $>1$ throughout the diurnal cycle, although the ratios for the Ohio Valley, Northeast, and Southeast remain $<0.75$.

- The hail-wind ratios reach a maximum CONUS-wide in the spring when the environment and convective mode are most supportive of hail-producing storms, and the ratios are at a relative minimum in July and August when warmer midlevel temperatures and larger, linear convective systems predominate. The lowest overall ratios (with the highest number of wind reports relative to hail) occur in the late fall and early winter when buoyancy is at a minimum.

The most useful aspect of this study for forecasters is the climatological likelihood of hail versus wind reports for given times of year/day and regions of the CONUS. First, hail-wind ratios consistently are lowest at night and highest during the late morning to midafternoon; this appears tied, at least in part, to convective mode. Second, when using all available reports, ratios are highest across the central CONUS and areas of complex/elevated terrain, while the ratios are lowest over the eastern CONUS and parts of the western CONUS. Reasons for this are both meteorological (i.e., related to convective mode) and nonmeteorological (i.e., related to population density and the availability of observations). And third, ratios are highest during the spring (March-May) when the environment is more conducive to severe hail production relative to severe wind; then ratios reach a relative minimum in mid- to late summer (July-August) as the warmer environment is relatively more favorable for severe wind than severe hail. Collectively, this climatological information may be helpful to forecasters when assessing hail and wind threats for convective storm warnings and deciding on whether to include hail size and/or wind gust tags. Moreover, this type of knowledge can be useful even for short-term outlooks of severe hail and wind (e.g., an overnight threat might prompt more of a wind concern than a hail concern).

One caveat worth noting is that there is a real possibility there are physical trends in hail and/or wind over the period of record, and that future changes in climate will, in turn, impact the use of the ratios from this study. For example, Tang et al. (2019) found an increase in days with favorable environments for large hail in parts of the central and eastern CONUS from 1979 to 2017. Trapp et al. (2019) suggested that the frequency of hail of about $\geq 35$-mm (1.4 in.) diameter will increase in the future over broad areas of the CONUS, but with decreases of $\geq 20$ - $\mathrm{mm}$ ( $0.8 \mathrm{in}$.) diameter hail in some areas. Brooks (2013) noted that future changes in CAPE and wind shear make it unclear on how individual hazards 
(hail and wind) will change, even though Brooks (2013) and Diffenbaugh et al. (2013) both indicated future increases in the occurrence of severe thunderstorm environments. Accordingly, these ratios likely will continue to be variable with time.

Finally, there are many local variations in the dataset that were not specifically addressed in this study. Therefore, the datasets used herein are available upon request for those interested in exploring the hail-wind relationships in more detail. This could be especially helpful for forecasters who are new to a given area. In addition, this approach of examining hail-wind ratios may be useful for other regions of the world to help gain a better understanding of the severe convective storm report climatology.

Acknowledgments. The authors thank Daryl Herzmann of the Iowa Environmental Mesonet at Iowa State University for providing Fig. 1 and information on hail and wind tag information in NWS severe thunderstorm warnings, Patrick Marsh of the Storm Prediction Center for maintaining the GIS database of convective storm reports, Alex Jacques from the University of Utah for providing information on historical mesonet data, and Mike Hudson of NWS Central Region for providing clarification on the Central Region 1-in. $(2.54 \mathrm{~cm})$ hail experiment from 2005 to 2009, as well as the CONUSwide IBW implementation in 2016. Early reviews of the manuscript by Keith Sherburn, Dan Miller, Jon Chamberlain, and Jeff Manion are greatly appreciated, as are the insightful and thorough comments from three anonymous reviewers, which were essential to further improving the manuscript. The scientific results and conclusions (as well as any views or opinions expressed herein) are those of the authors and do not necessarily reflect the views of NWS, NOAA, or the Department of Commerce.

\section{REFERENCES}

Allen, J. T., and M. K. Tippett, 2015: The characteristics of United States hail reports: 1955-2014. Electron. J. Severe Storms Meteor., 10 (3), https://ejssm.org/ojs/index.php/ejssm/article/ viewArticle/149.

Amburn, S. A., and P. L. Wolf, 1997: VIL density as a hail indicator. Wea. Forecasting, 12, 473-478, https://doi.org/10.1175/15200434(1997)012<0473:VDAAHI>2.0.CO;2.

Ashley, W. S., A. M. Haberlie, and J. Strohm, 2019: A climatology of quasi-linear convective systems and their hazards in the United States. Wea. Forecasting, 34, 1605-1631, https:// doi.org/10.1175/WAF-D-19-0014.1.

Banta, R. M., 1990: The role of mountain flows in making clouds. Atmospheric Processes over Complex Terrain, Meteor. Monogr., No. 45, Amer. Meteor. Soc., 229-283.

Blair, S. F., D. R. Deroche, J. M. Boustead, J. W. Leighton, B. L. Barjenbruch, and W. P. Gargen, 2011: A radar-based assessment of the detectability of giant hail. Electron. J. Severe
Storms Meteor., 6 (7), https://www.ejssm.org/ojs/index.php/ ejssm/article/viewArticle/87.

_ - and Coauthors, 2017: High-resolution hail observations: Implications for NWS warning operations. Wea. Forecasting, 32, 1101-1119, https://doi.org/10.1175/WAF-D-16-0203.1.

Brooks, H. E., 2013: Severe thunderstorms and climate change. Atmos. Res., 123, 129-138, https://doi.org/10.1016/ j.atmosres.2012.04.002.

_ National Weather Service tornado warnings. Wea. Forecasting, 33, 1501-1511, https://doi.org/10.1175/WAF-D-18-0120.1.

Carlson, T. N., S. G. Benjamin, G. S. Forbes, and Y.-F. Li, 1983: Elevated mixed layers in the regional severe storm environment: Conceptual model and case studies. Mon. Wea. Rev., 111, 1453-1474, https://doi.org/10.1175/1520-0493(1983)111<1453: EMLITR > 2.0.CO;2.

Casteel, M. A., 2016: Communicating increased risk: An empirical investigation of the National Weather Service's impact-based warnings. Wea. Climate Soc., 8, 219-232, https://doi.org/ 10.1175/WCAS-D-15-0044.1.

Cavanaugh, D. E., and J. A. Schultz, 2012: WSR-88D signatures associated with one inch hail in the Southern Plains. Electron. J. Oper. Meteor., 13 (1), 1-14, http://nwafiles.nwas.org/ej/pdf/ 2012-EJ1.pdf.

Coniglio, M. C., and D. J. Stensrud, 2004: Interpreting the climatology of derechos. Wea. Forecasting, 19, 595-605, https:// doi.org/10.1175/1520-0434(2004)019<0595:ITCOD > 2.0.CO;2.

Corfidi, S. F., R. H. Johns, and M. A. Darrow, 2016: The Great Basin derecho of 31 May 1994. Wea. Forecasting, 31, 917-935, https://doi.org/10.1175/WAF-D-15-0178.1.

Crum, T. D., and R. L. Alberty, 1993: The WSR-88D and the WSR88D operational support facility. Bull. Amer. Meteor. Soc., 74, 1669-1687, https://doi.org/10.1175/1520-0477(1993)074<1669: TWATWO $>2.0 . \mathrm{CO} ; 2$.

_ R. E. Saffle, and J. W. Wilson, 1998: An update on the NEXRAD program and future WSR-88D support to operations. Wea. Forecasting, 13, 253-262, https://doi.org/10.1175/ 1520-0434(1998)013<0253:AUOTNP > 2.0.CO;2.

Diffenbaugh, N. S., M. Scherer, and R. J. Trapp, 2013: Robust increases in severe thunderstorm environments in response to greenhouse forcing. Proc. Natl. Acad. Sci. USA, 110, 1636116366, https://doi.org/10.1073/pnas.1307758110.

Doswell, C. A., III, H. E. Brooks, and M. P. Kay, 2005: Climatological estimates of daily local nontornadic severe thunderstorm probability for the United States. Wea. Forecasting, 20, 577-595, https:// doi.org/10.1175/WAF866.1.

Edwards, R., J. T. Allen, and G. W. Carbin, 2018: Reliability and climatological impacts of convective wind estimations. J. Appl. Meteor. Climatol., 57, 1825-1845, https://doi.org/ 10.1175/JAMC-D-17-0306.1.

Ferree, J. T., J. M. Looney, and K. R. Waters, 2006: NOAA/ National Weather Services' storm-based warnings. 23rd Conf. on Severe Local Storms, St. Louis, MO, Amer. Meteor. Soc., 11.6, https://ams.confex.com/ams/pdfpapers/115513.pdf.

Fleegel, S., and M. Dutter, 2012: A cloud-to-ground (CG) lightning climatology for the Lake Superior region. 37th Natl. Wea. Assoc. Annual Meeting, Madison, WI, National Weather Association, P2.19, https://nwas.org/annual-meeting-events/ past-meetings/2012-annual-meeting/.

Friday, E. W., Jr., 1994: The modernization and associated restructuring of the National Weather Service: An overview. Bull. Amer. Meteor. Soc., 75, 43-52, https://doi.org/10.1175/ 1520-0477(1994)075<0043:TMAARO > 2.0.CO;2. 
Guastini, C. T., and L. F. Bosart, 2016: Analysis of a progressive derecho climatology and associated formation environments. Mon. Wea. Rev., 144, 1363-1382, https://doi.org/10.1175/MWRD-15-0256.1.

Harrison, D. R., and C. D. Karstens, 2017: A climatology of operational storm-based warnings: A geospatial analysis. Wea. Forecasting, 32, 47-60, https://doi.org/10.1175/WAFD-15-0146.1.

Horel, J., and Coauthors, 2002: MesoWest: Cooperative mesonets in the western United States. Bull. Amer. Meteor. Soc., 83, 211-225, https://doi.org/10.1175/1520-0477(2002)083<0211: MCMITW $>2.3 . \mathrm{CO} ; 2$.

Hudson, M. J., P. Browning, K. Runk, K. Harding, K. Galluppi, J. Losego, and B. Montz, 2013: Central region impact-based warnings demonstration: Helping to build a weather-ready nation. Eighth Symp. on Policy and Socio-Economic Research, Austin, TX, Amer. Meteor. Soc., JPD1.1, https://ams.confex.com/ ams/93Annual/webprogram/Paper222556.html.

_, R. Wagenmaker, G. Mann, B. Smith, R. Thompson, and J. Ferree, 2015: Science that drives service: The NWS impactbased warning demonstration. Third Symp. on Building a Weather-Ready Nation: Enhancing Our Nation's Readiness, Responsiveness, and Resilience to High Impact Weather Events, Phoenix, AZ, Amer. Meteor. Soc., TJ4.1, https://ams.confex.com/ ams/95Annual/webprogram/Paper260627.html.

Jirak, I. L., C. J. Melick, and S. J. Weiss, 2014: Combining probabilistic ensemble information from the environment with simulated storm attributes to generate calibrated probabilities of severe weather hazards. 27th Conf. on Severe Local Storms, Madison, WI, Amer. Meteor. Soc., 2.5, https://ams.confex.com/ams/27SLS/webprogram/Manuscript/ Paper254649/SLS2014_Cal_Hazards_exabs_Final.pdf.

Johns, R. H., and C. A. Doswell III, 1992: Severe local storms forecasting. Wea. Forecasting, 7, 588-612, https://doi.org/ 10.1175/1520-0434(1992)007<0588:SLSF > 2.0.CO;2.

Kelly, D. L., J. T. Schaefer, and C. A. Doswell III, 1985: Climatology of nontornadic severe thunderstorm events in the United States. Mon. Wea. Rev., 113, 1997-2014, https://doi.org/10.1175/15200493(1985)113<1997:CONSTE > 2.0.CO;2.

Klimowski, B. A., M. J. Bunkers, M. R. Hjelmfelt, and J. N. Covert, 2003: Severe convective windstorms over the northern High Plains of the United States. Wea. Forecasting, 18, 502-519, https:// doi.org/10.1175/1520-0434(2003)18<502:SCWOTN $>2.0 . C O ; 2$.

Kramar, M. R., and J. J. Waters, 2010: Predicting severe hail in the WFO LWX county warning area: Toward increased accuracy in hail size forecasts. 24th Conf. on Hydrology, Atlanta, GA, Amer. Meteor. Soc., 447, https://ams.confex.com/ams/ pdfpapers/163806.pdf.

Mahmood, R., and Coauthors, 2017: Mesonets: Mesoscale weather and climate observations for the United States. Bull. Amer. Meteor. Soc., 98,1349-1361, https://doi.org/10.1175/BAMS-D15-00258.1.

Maldonado-Jaime, J., P. Schumacher, and A. Ferguson, 2019: Impacts of radar distance, time of day and year on severe warning performance over the North Central United States. 23rd Severe Storms and Doppler Radar Conf., Ankeny, IA, National Weather Association, 2.2, http://iowa-nwa.com/ conference/files/2019_NWA_Agenda.pdf.

Monteverdi, J. P., and J. Quadros, 1994: Convective and rotational parameters associated with three tornado episodes in Northern and Central California. Wea. Forecasting, 9, 285-300, https://doi.org/10.1175/1520-0434(1994)009<0285: CARPAW $>2.0 . \mathrm{CO} ; 2$.
— echo in the San Joaquin Valley, California. Wea. Forecasting, 11, 246-261, https://doi.org/10.1175/1520-0434(1996)011<0246: ASTWHE $>2.0 . \mathrm{CO} ; 2$

NWS, 2018: WFO severe weather products specification. National Weather Service Instruction 10-511, 58 pp., http:// www.nws.noaa.gov/directives/sym/pd01005011curr.pdf.

Ortega, K. L., 2018: Evaluating multi-radar, multi-sensor products for surface hail-fall diagnosis. Electron. J. Severe Storms Meteor., 13 (1), https://www.ejssm.org/ojs/index.php/ejssm/ article/viewArticle/163.

—-, T. M. Smith, K. L. Manross, A. G. Kolodziej, K. A. Scharfenberg, A. Witt, and J. J. Gourley, 2009: The Severe Hazards Analysis and Verification Experiment. Bull. Amer. Meteor. Soc., 90, 1519-1530, https://doi.org/10.1175/ 2009BAMS2815.1.

Parker, M. D., 2018: External vs. self-organization of nocturnal MCSs from PECAN. 29th Conf. on Severe Local Storms, Stowe, VT, Amer. Meteor. Soc., 4.5, https://ams.confex.com/ ams/29SLS/webprogram/Paper348312.html.

Potvin, C. K., C. Broyles, P. S. Skinner, H. E. Brooks, and E. Rasmussen, 2019: A Bayesian hierarchical modeling framework for correcting reporting bias in the U.S. tornado database. Wea. Forecasting, 34, 15-30, https://doi.org/10.1175/ WAF-D-18-0137.1.

Reif, D. W., and H. B. Bluestein, 2017: A 20-year climatology of nocturnal convection initiation over the central and southern Great Plains during the warm season. Mon. Wea. Rev., 145, 1615-1639, https://doi.org/10.1175/MWR-D-16-0340.1.

Rogers, J. W., R. L. Thompson, and P. T. Marsh, 2014: Potential applications of a CONUS sounding climatology developed at the Storm Prediction Center. 27th Conf. on Severe Local Storms, Madison, WI, Amer. Meteor. Soc., P10.145, https://ams.confex.com/ams/27SLS/webprogram/Manuscript/ Paper255385/Extended\%20abstract.pdf.

Sherburn, K. D., and M. D. Parker, 2014: Climatology and ingredients of significant severe convection in high-shear, lowCAPE environments. Wea. Forecasting, 29, 854-877, https:// doi.org/10.1175/WAF-D-13-00041.1.

Shulski, M., S. Cooper, G. Roebke, and A. Dutcher, 2018: The Nebraska Mesonet: Technical overview of an automated state weather network. J. Atmos. Oceanic Technol., 35, 2189-2200, https://doi.org/10.1175/JTECH-D-17-0181.1.

Smith, B. T., R. L. Thompson, J. S. Grams, C. Broyles, and H. E. Brooks, 2012: Convective modes for significant severe thunderstorms in the contiguous United States. Part I: Storm classification and climatology. Wea. Forecasting, 27, 11141135, https://doi.org/10.1175/WAF-D-11-00115.1.

_- T. E. Castellanos, A. C. Winters, C. M. Mead, A. R. Dean, and R. L. Thompson, 2013: Measured severe convective wind climatology and associated convective modes of thunderstorms in the contiguous United States, 2003-09. Wea. Forecasting, 28, 229-236, https://doi.org/10.1175/ WAF-D-12-00096.1.

Stelten, S., and W. A. Gallus, 2017: Pristine nocturnal convective initiation: A climatology and preliminary examination of predictability. Wea. Forecasting, 32, 1613-1635, https://doi.org/ 10.1175/WAF-D-16-0222.1.

Sutter, D., and S. Erickson, 2010: The time cost of tornado warnings and the savings with storm-based warnings. Wea. Climate Soc., 2, 103-112, https://doi.org/10.1175/2009WCAS1011.1.

Tang, B. H., V. A. Gensini, and C. R. Homeyer, 2019: Trends in United States large hail environments and observations. 
Climate Atmos. Sci., 2, 45, https://doi.org/10.1038/S41612-0190103-7.

Trapp, R. J., D. M. Wheatley, N. T. Atkins, R. W. Przybylinski, and R. Wolf, 2006: Buyer beware: Some words of caution on the use of severe wind reports in postevent assessment and research. Wea. Forecasting, 21, 408-415, https://doi.org/10.1175/ WAF925.1.

, K. A. Hoogewind, and S. Lasher-Trapp, 2019: Future changes in hail occurrence in the United States determined through convection-permitting dynamical downscaling.
J. Climate, 32, 5493-5509, https://doi.org/10.1175/JCLI-D18-0740.1.

Weiss, S. J., and M. D. Vescio, 1998: Severe local storm climatology 1955-1996: Analysis of reporting trends and implications for NWS operations. Preprints, 19th Conf. on Severe Local Storms, Minneapolis, MN, Amer. Meteor. Soc., 536-539.

_ , J. A. Hart, and P. R. Janish, 2002: An examination of severe thunderstorm wind report climatology: 1970-1999. Preprints, 21st Conf. on Severe Local Storms, San Antonio, TX, Amer. Meteor. Soc., 446-449. 